\title{
Tumor cell-activated CARD9 signaling contributes to metastasis-associated macrophage polarization
}

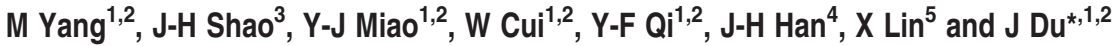

\begin{abstract}
Macrophages are critical immune effector cells of the tumor microenvironment that promote seeding, extravasation and persistent growth of tumor cells in primary tumors and metastatic sites. Tumor progression and metastasis are affected by dynamic changes in the specific phenotypes of macrophage subpopulations; however, the mechanisms by which tumor cells modulate macrophage polarization remain incompletely understood. Caspase recruitment domain-containing protein 9 (CARD9) is a central adaptor protein of innate immune responses to extracellular pathogens. We report that increased CARD9 expression is primarily localized in infiltrated macrophages and significantly associated with advanced histopathologic stage and the presence of metastasis. Using CARD9-deficient (CARD9 ${ }^{-l-}$ ) mice, we show that bone marrow-derived CARD9 promotes liver metastasis of colon carcinoma cells. Mechanistic studies reveal that CARD9 contributes to tumor metastasis by promoting metastasis-associated macrophage polarization through activation of the nuclear factor-kappa B signaling pathway. We further demonstrate that tumor cell-secreted vascular endothelial growth factor facilitates spleen tyrosine kinase activation in macrophages, which is necessary for formation of the CARD9-B-cell lymphoma/leukemia 10-mucosa-associated lymphoid tissue lymphoma translocation protein 1 complex. Taken together, our results indicating that CARD9 is a regulator of metastasis-associated macrophages will lead to new insights into evolution of the microenvironments supporting tumor metastasis, thereby providing targets for anticancer therapies.
\end{abstract}

Cell Death and Differentiation (2014) 21, 1290-1302; doi:10.1038/cdd.2014.45; published online 11 April 2014

Malignant dissemination is not an exclusively cancer cell-autonomous process; other constituents of the tumor microenvironment, such as inflammatory cells, heavily influence cancer progression. ${ }^{1,2}$ Macrophages are prominent components of leukocyte infiltrates and frequently respond to microenvironmental signals. Substantial clinical and experimental evidence indicates that macrophages facilitate tumor metastasis, support tumor-associated angiogenesis, promote tumor cell invasion and migration, and suppress antitumor immune responses. ${ }^{3-7}$ Therefore, the presence of a high number of macrophages in various types of cancer is associated with poor prognosis in human studies. ${ }^{8-12}$

Macrophages show functionally polarized phenotypes in a signal- and context-dependent manner. Phenotyping studies revealed that metastasis-associated macrophages differ from CD11c-positive lung interstitial resident macrophages; this prometastatic macrophage population has a distinct phenotype that is found not only in these experimental models but also in metastasis derived from autochthonous (spontaneous and native) models. ${ }^{13,14}$ Recent studies have strengthened the idea that macrophages and tumor cells act in concert to promote the progression of the tumor mass. Through interactions between tumor cells and macrophages, macrophages undergo a process of maturation or 'education' within the tumor microenvironment. Despite emerging appreciation for cancer - immune cell interactions in metastasis, our understanding of how immune cells, including macrophages, respond to cancer signals and turn on their prometastatic phenotype remains unclear.

Caspase recruitment domain-containing protein 9 (CARD9) is a central regulator of innate immunity that is highly expressed in myeloid cells, particularly in macrophages and in dendritic cells. ${ }^{15}$ CARD9 signaling mediates mammalian innate immune responses against selected fungi, bacteria and viruses and can prime and shape adaptive immunity. ${ }^{16}$ Aberrant activation of CARD9, either through genetic mutations or through environmental factors, could result in pathologic immune cell activation, causing inflammatory diseases or certain cancers. It is important to note that ectopic overexpression of CARD9 was found in gastric B-cell lymphoma specimens, suggesting that aberrant CARD9 expression in B cells could contribute to the survival or proliferation of tumor cells potentially via nuclear factor-kappa $\mathrm{B}(\mathrm{NF}-\kappa \mathrm{B})$ activation. ${ }^{17,18} \mathrm{CARD} 9$ has been shown to have a prominent role in the pathogenesis of immune responses and

${ }^{1}$ Department of Cardiac and Vascular Biology, Beijing Anzhen Hospital, Capital Medical University, Beijing, China; ${ }^{2}$ The Key Laboratory of Remodeling-Related Cardiovascular Diseases, Capital Medical University, Ministry of Education, Beijing Institute of Heart Lung and Blood Vessel Diseases, Beijing, China; ${ }^{3}$ Department of Surgery, The Second Affiliated Hospital to Nanchang University, Jiangxi, China; ${ }^{4}$ State Key Laboratory of Cellular Stress Biology and School of Life Sciences, Xiamen University, Fujian, China and ${ }^{5}$ Department of Molecular and Cellular Oncology, University of Texas, MD Anderson Cancer Center, Houston, TX, USA

${ }^{*}$ Corresponding author: J Du, Beijing Anzhen Hospital, Capital Medical University or The Key Laboratory of Remodeling-Related Cardiovascular Diseases, Capital Medical University, Ministry of Education, Beijing Institute of Heart Lung and Blood Vessel Diseases, No. 2 Anzhen Road, Chaoyang District, Beijing 100029, China. Tel: +86 10 64456030; Fax: +86 10 64451050; E-mail: jdu@bcm.edu

Abbreviations: CARD9, caspase recruitment domain-containing protein 9; NF- $\kappa$ B, nuclear factor-kappa B; IKK, inhibitor of $\kappa$ B kinase; I- $\kappa$ B, inhibitor of $\kappa$ B; Syk, spleen tyrosine kinase; BMDMs, bone marrow-derived macrophages; TAMs, tumor-associated macrophages; IL, interleukin; TGF- $\beta$, transforming growth factor- $\beta$; CCR2, C-C motif chemokine receptor 2; VEGFR1, vascular endothelial growth factor receptor 1; MALT1, mucosa-associated lymphoid tissue lymphoma translocation protein 1; BCL10, B-cell lymphoma/leukemia 10; CCL, chemokine (C-C motif) ligand; FIZZ1, found in inflammatory zone 1; CXCL, chemokine (C-X-C motif) ligand; iNOS, inducible nitric oxide synthase; MIG, monokine-induced by gamma interferon; VEGF, vascular endothelial growth factor

Received 27.8.13; revised 27.2.14; accepted 07.3.14; Edited by JP Medema; published online 11.4.14 
inflammatory disorders; however, little is known about the role of CARD9 in tumor metastasis, especially regarding its function in tumor-infiltrating macrophages.

The goal of this study was to determine the functional contributions of CARD9 to cancer metastasis and to elucidate the underlying signaling pathways of CARD9 as a regulator of macrophage polarization that enhances cancer metastasis. This work thus highlights a novel function of CARD9 in the tumor microenvironment and newly identifies it as a mediator of the metastasis-promoting functions of macrophages with predictive value for clinical outcomes.

\section{Results}

CARD9 is expressed in infiltrating macrophages of human colon carcinoma and is highly expressed during colon carcinoma progression. To establish the role of the CARD protein family in tumor progression, we examined the expression of CARD family proteins in human colon carcinoma and adjacent normal colon tissues. Quantitative RT-PCR revealed that CARD9 mRNA was prominently expressed and highly enriched in colon carcinoma specimens compared with healthy tissues (Figure 1a). In addition,
CARD9 mRNA was highly expressed in metastatic foci in the liver after intrasplenic injection of SL4 cells in wild-type (WT) mice (Figure 1b). Immunohistochemical staining demonstrated low expression of CARD9 protein in adjacent normal colon tissues (Figure 1c). In contrast, CARD9 expression in colon carcinoma tissues was markedly increased, primarily in tumor-infiltrating leukocytes but not in cancer cells (Figure 1c). Moreover, as shown in Figure 1d, CARD9 immunoreactivity was observed in macrophage-like cells located in lymph nodes with histologic detectable metastasis. Poorly differentiated metastasis of human colon carcinoma expressed a significantly higher level of CARD9 $(13.17 \pm 1.35 \%)$, whereas quantification showed that the CARD9-positive staining areas were $4.04 \pm 0.52 \%$ in moderately differentiated metastasis and $1.99 \pm 0.41 \%$ in well-differentiated metastasis (Figure 1d). CD68 (a macrophage marker) immunostaining showed that macrophage density was significantly increased in poorly differentiated metastasis compared with moderately differentiated and well differentiated metastasis (Figure 1d). A significant positive correlation was observed between CARD9 immunohistochemical expression and macrophage density (Spearman rank correlation coefficient $(r)=0.85, P<0.0001)$.

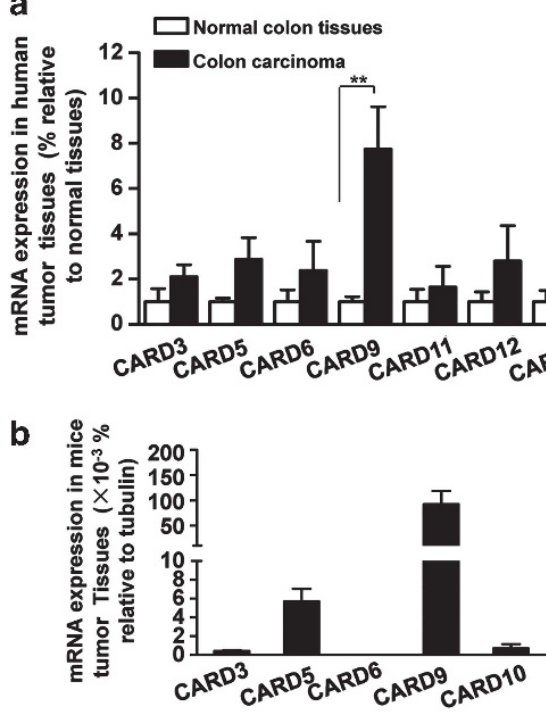

c

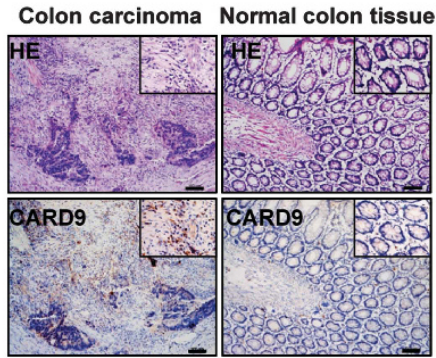

d
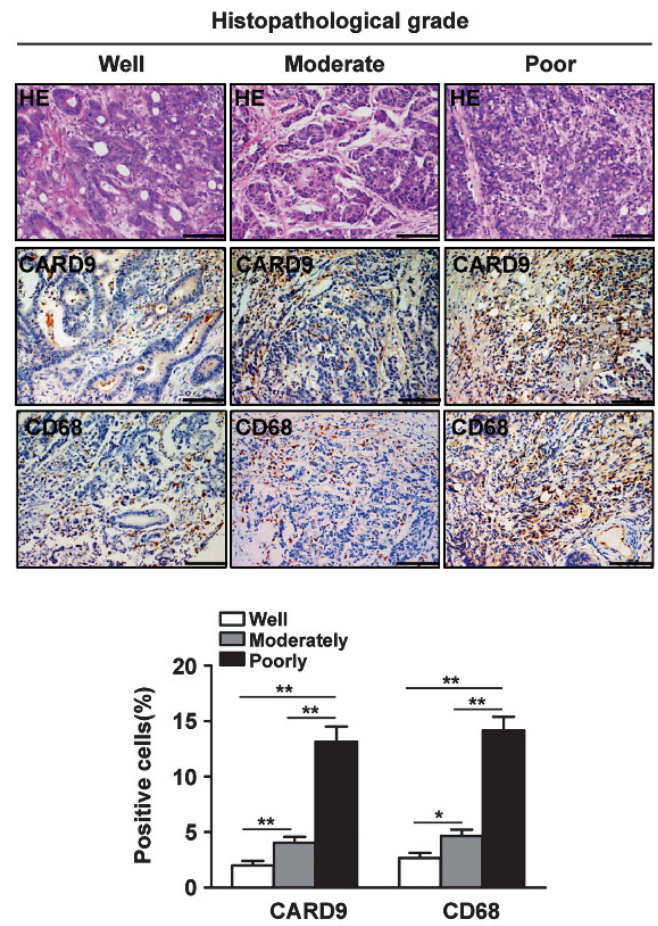

Figure 1 Expression of CARD9 in tumor tissues. (a) Quantitative real-time polymerase chain reaction (PCR) analysis of the mRNA level of CARD family members in human colon carcinoma and adjacent normal colon tissues. Data are mean \pm S.E.M. for $n=10$ per group. GAPDH was a normalization control. ${ }^{* \star} P<0.01$ versus adjacent normal colon tissues. (b) Quantitative real-time PCR analysis of the mRNA level of CARD family members in metastatic foci in the liver after intrasplenic injection of SL4 cells in WT mice ( $n=10$ mice per group). Tubulin was a normalization control. (c) HE staining and immunohistochemical analysis of CARD9 expression in human colon carcinoma and adjacent normal colon tissues $(\times 100$ magnification and scale bars $=100 \mu \mathrm{m})$. (d) Immunohistochemical analysis of CARD9 expression or macrophage marker CD68 expression in lymph node metastasis of human colon carcinoma ( $\times 200$ magnification and scale bars $=100 \mu \mathrm{m}$ ). Quantitative analysis of CARD9 and CD68 expression in metastatic foci of lymph node at different histologic grade ( $n=10$ samples per group, with 10 fields per samples). ${ }^{*} P<0.05 .{ }^{* *} P<0.01$ 
To further confirm CARD9 expression, western blot was performed in different types of cultured mouse cells. As shown in Supplementary Figure 1a, CARD9 was highly expressed in murine macrophages, including bone marrow (BM)-derived macrophages (BMDMs) and the RWA 264.7 cell line, but hardly detected in SL4 cells. Furthermore, in BMDMs or RAW 264.7 cells, the level of CARD9 protein was not different in the presence or absence of cocultured SL4 cells (Supplementary Figure 1b). These results suggest that high levels of CARD9 in progressing colon carcinoma are due to accumulation of macrophages in the tumor microenvironment.

CARD9 deficiency inhibits tumor metastasis. To investigate the role of CARD9 in liver metastasis of colon carcinoma cells, SL4 cells were injected into the spleens of WT and CARD9 $^{-1-}$ mice. As shown in Figure $2 a$, gross inspection demonstrated a marked increase of liver weight in WT mice because of multiple hepatic tumor nodules compared with the normal liver weight, whereas livers from CARD9 ${ }^{-1-}$ mice showed fewer tumor foci and decreased tumoroccupied weight relative to that in WT mice (Figure 2a).
Moreover, histologic analysis showed that the average number of micrometastatic nodules significantly decreased in $\mathrm{CARD9}^{-1-}$ mice compared with that in WT mice (Figure 2b). To further confirm the role of CARD9 in the metastatic process, we evaluated liver metastasis in WT and $\mathrm{CARD}^{-1-}$ mice using murine colon cancer SL4 cells engineered to express firefly luciferase (SL4-Luc). Bioluminescence imaging showed a significant decrease in liver metastatic foci of CARD9 ${ }^{-1-}$ mice compared with WT mice (Figure 2c). Taken together, these results support the notion that CARD9 has a critical role in facilitating metastasis.

CARD9 expression in BM-derived leukocytes promotes tumor metastasis. To further explore whether the reduced tumor metastasis in CARD9 ${ }^{-1-}$ mice was attributable to the lack of CARD9 expression by tumor-infiltrating leukocytes, we transplanted WT BM of syngeneic mice into lethally irradiated CARD9 ${ }^{-1}$ - recipients $\left(\mathrm{WT}_{\mathrm{BM}} \rightarrow \mathrm{CARD9}^{-1}-\right.$ mice) or performed the reverse experiment $\left(\mathrm{CARD}^{-1-} \mathrm{BM} \rightarrow \mathrm{WT}\right.$ mice). As shown in Figure 3a, tumor metastasis was inhibited in $\mathrm{CARD9}^{-1-}{ }_{\mathrm{BM}} \rightarrow \mathrm{WT}$ mice, compared with $\mathrm{WT}_{\mathrm{BM}} \rightarrow \mathrm{WT}$ a

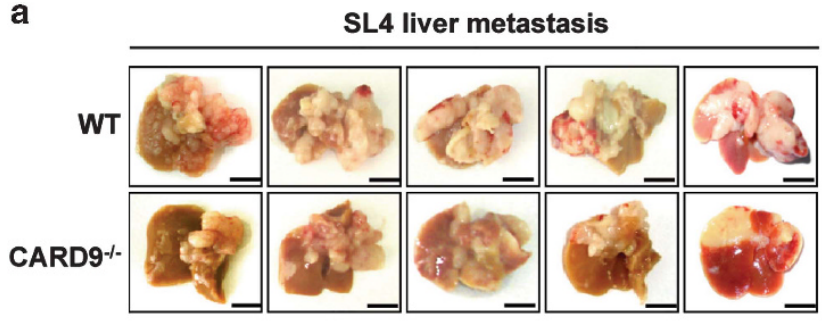

b

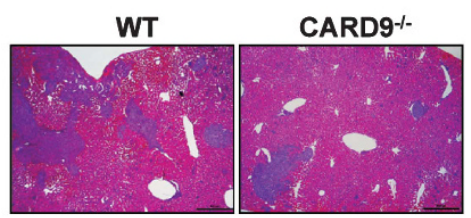

C

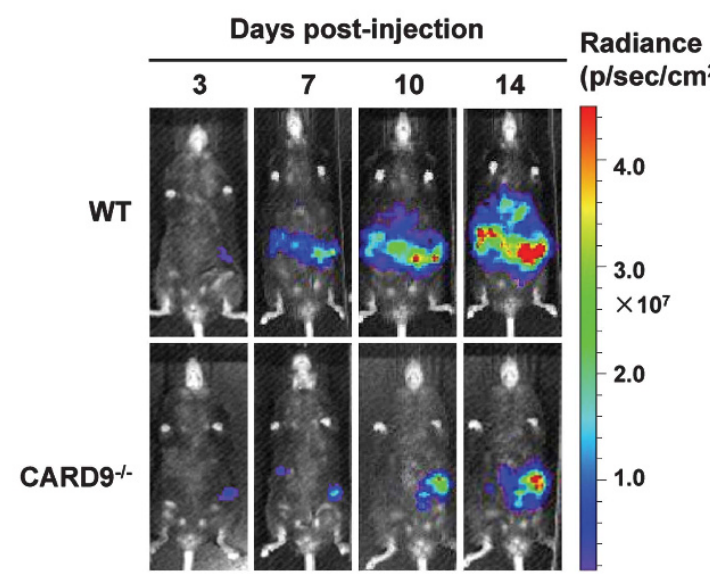

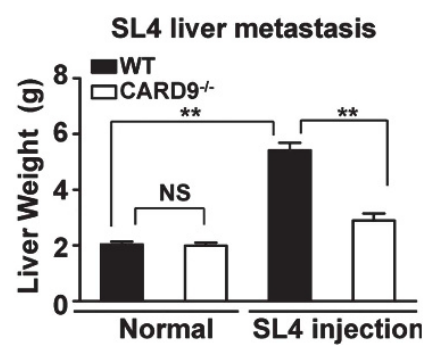

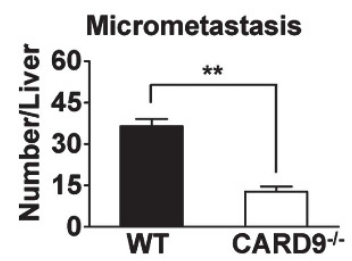

Figure 2 CARD9 deficiency inhibits tumor metastasis. (a) Gross examination of hepatic tumor metastasis of colon cancer after intrasplenic injection of SL4 cells in WT and CARD9 $^{-1-}$ mice. SL4 cells $\left(1 \times 10^{6}\right)$ were injected into the spleen of WT and CARD9 ${ }^{-1-}$ mice. Mice were killed at 14 days after tumor injection to determine the incidence of liver metastasis and tumor weight. The normal livers from WT or CARD ${ }^{-1-}$ mice as control groups. Scale bars $=1 \mathrm{~mm}$. Data are mean \pm S.E.M. for $n=10$ mice. NS indicates not significant. ${ }^{* *} P<0.01$. (b) The analysis of micrometastasis was performed with HE staining in metastasized foci after intrasplenic injection of SL4 cells in WT and CARD9 ${ }^{-1-}$ mice. Number of micrometastatic lesions per one representative cross section of the livers from each mouse ( $\times 40$ magnification and Scale bars $=500 \mu \mathrm{m})$. Data are mean \pm S.E.M. for $n=10$ mice with 10 fields per animal. ${ }^{*} P<0.01$. (c) Bioluminescence images at the indicated times (days) post-injection with luciferase-expressing SL4 cells in WT and CARD9 $^{-1-}$ mice. Quantification of total photon flux (photons per second) per animal over the indicated time periods. Data are mean \pm S.E.M. for $n=8$ mice per group. ${ }^{* *} P<0.01$ 
mice, to a similar extent as in $\mathrm{CARD9}^{-/-} \mathrm{BM} \rightarrow \mathrm{CARD9}^{-/-}$ mice. Conversely, tumor metastasis was inhibited in $\mathrm{CARD9}^{-1-}{ }_{\mathrm{BM}} \rightarrow \mathrm{CARD}^{-1-}$ mice compared with $\mathrm{WT}_{\mathrm{BM}} \rightarrow$ WT mice, which could be rescued by transplantation of WT $\mathrm{BM}$ in $\mathrm{CARD}^{-1-}$ mice $\left(\mathrm{WT}_{\mathrm{BM}} \rightarrow \mathrm{CARD} 9^{-1-}\right.$ mice) to similar levels as observed in $\mathrm{WT}_{\mathrm{BM}} \rightarrow \mathrm{WT}$ mice (Figure $3 \mathrm{a}$ ), indicating that WT BM is sufficient to restore tumor metastasis in CARD9 ${ }^{-1-}$ mice. These data were confirmed by histomorphometric measurement of tumor weight 14 days after SL4-Luc cells inoculation (Figure 3b). Thus, CARD9 expression in BM-derived leukocytes is required for enhanced tumor metastasis.

CARD9 expressed in infiltrating macrophages increases tumor-promoting cytokine levels during tumor metastasis. To analyze the cellular source of CARD9 expression among tumor-infiltrating leukocytes, tumor sections were immunostained with the macrophage marker F4/80 and anti-CARD9 antibody to assess CARD9 expression in the tumor stroma. CARD9 was abundantly expressed in macrophages, with no CARD9 expression in $\mathrm{CARD}^{-1-}$ macrophages (Figure $4 \mathrm{a}$ ). We further compared the relative proportions of macrophages (F4/80), T helper cells (CD3, CD4) or cytotoxic T lymphocytes (CD3, CD8) in hepatic metastatic tumors from CARD9 ${ }^{-1-}$ or WT mice. As shown in Supplementary Figure 2, the proportion of infiltrating $\mathrm{CD}_{4} 5^{+} \mathrm{F} 4 / 80^{+}$cells, $\mathrm{CD}^{+}$or $\mathrm{CD} 8^{+}$ $\mathrm{T}$ lymphocytes in hepatic metastatic tumors was not significantly different between CARD9 ${ }^{-1-}$ and WT mice. Flow cytometric analysis revealed that macrophages expressed significantly less interleukin-10 (IL-10) and IL-1 $\alpha$ (tumor-promoting cytokines), but higher level of antitumor cytokine IL-12 in the metastatic foci of CARD9 ${ }^{-/-}$ mice than WT mice (Figure 4b).

To determine whether CARD9 regulates macrophage polarization in the tumor microenvironment, we examined the expression of cytokines in metastatic tumor tissues. The expression of IL-13, IL-4, IL-18 and transforming growth factor- $\beta$ (TGF- $\beta$ ) (M2-specific cytokines) was markedly decreased in hepatic metastatic tumors of CARD9 ${ }^{-1-}$ mice compared with that in WT mice (Figure 4c). The multiplex inflammatory profile revealed that CARD ${ }^{-1-}$ BMDMs with SL4 cell treatment expressed lower levels of pro-metastatic genes IL-10, IL- $1 \alpha$, TGF- $\beta$ and vascular endothelial growth factor receptor 1 (VEGFR1) mRNA, but higher levels of IL-12p40 and IL-12p35 mRNA than WT BMDMs following coculture with SL4 cells (Supplementary Figure 3). Thus, CARD9 enhances tumor-promoting cytokine expression in macrophages.

Tumor cell education of macrophages toward metastasisassociated polarization is mediated by CARD9. We analyzed macrophage phenotype and CARD9 expression in normal colonic mucosa and colon carcinoma specimens. As shown in Figure 5a, CD68-positive macrophages were rarely detected in normal tissues, but macrophages

a
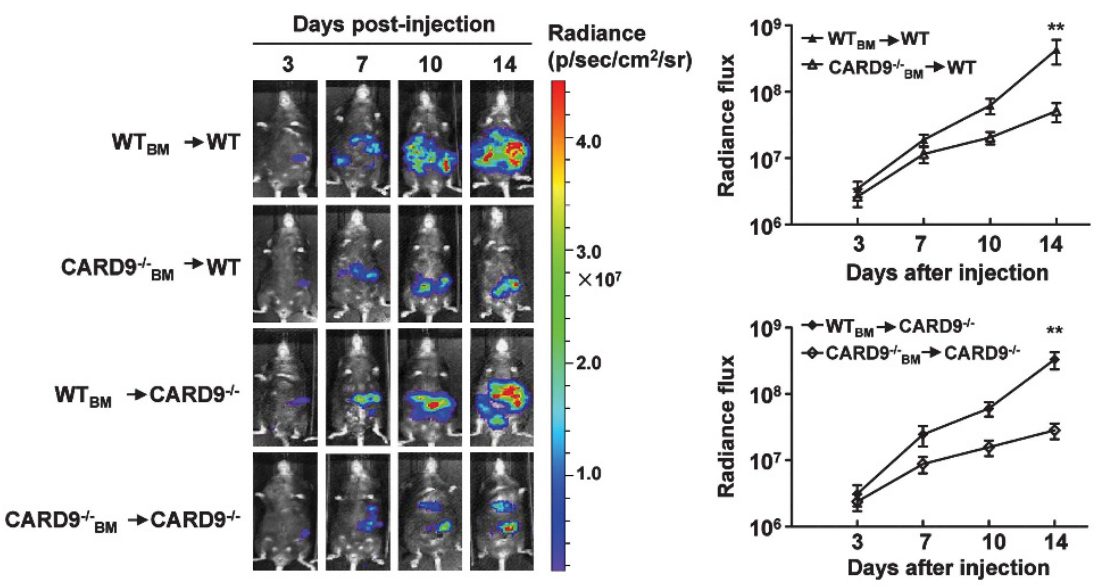

b
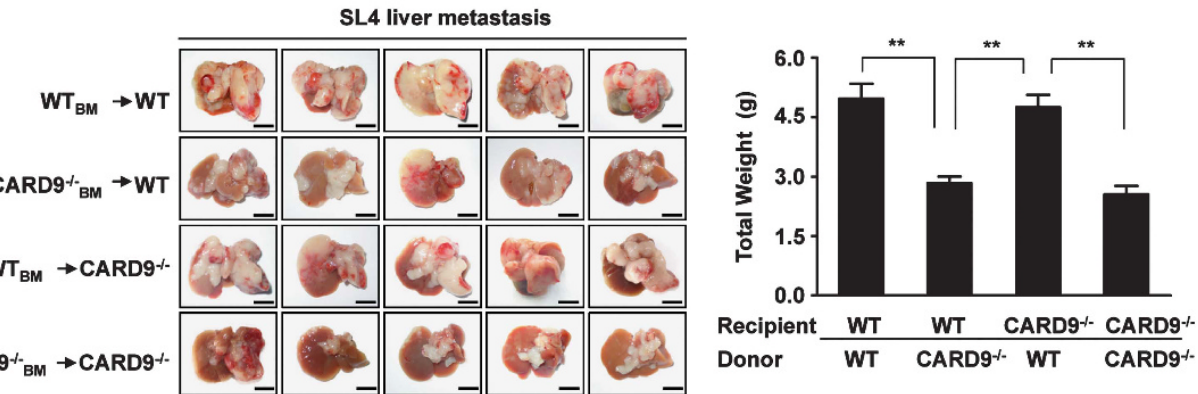

Figure 3 CARD9 contributing to tumor metastasis is delivered by BM-derived cells. (a) Recipient WT and CARD9 ${ }^{-1-}$ mice were lethally irradiated and reconstituted with BM from donor CARD9 ${ }^{-1-}$ or WT mice. After 8 weeks, chimeras were intrasplenically injected with $1.0 \times 10^{6}$ SL4-Luc cells. At the indicated days after inoculation, bioluminescence images were acquired. Quantification of data was performed by analyzing the total flux of photons/second in the abdominal regions of experimental animals at indicated time points. Data are mean \pm S.E.M. for $n=8$ mice per group. ${ }^{*} P<0.01$. (b) On day 14 after SL4-Luc cells inoculation, mice were killed and liver weight in chimeras was measured. Scale bars $=1 \mathrm{~mm}$. Data are mean \pm S.E.M. for $n=8$ mice per group. ${ }^{\star \star} P<0.01$ 

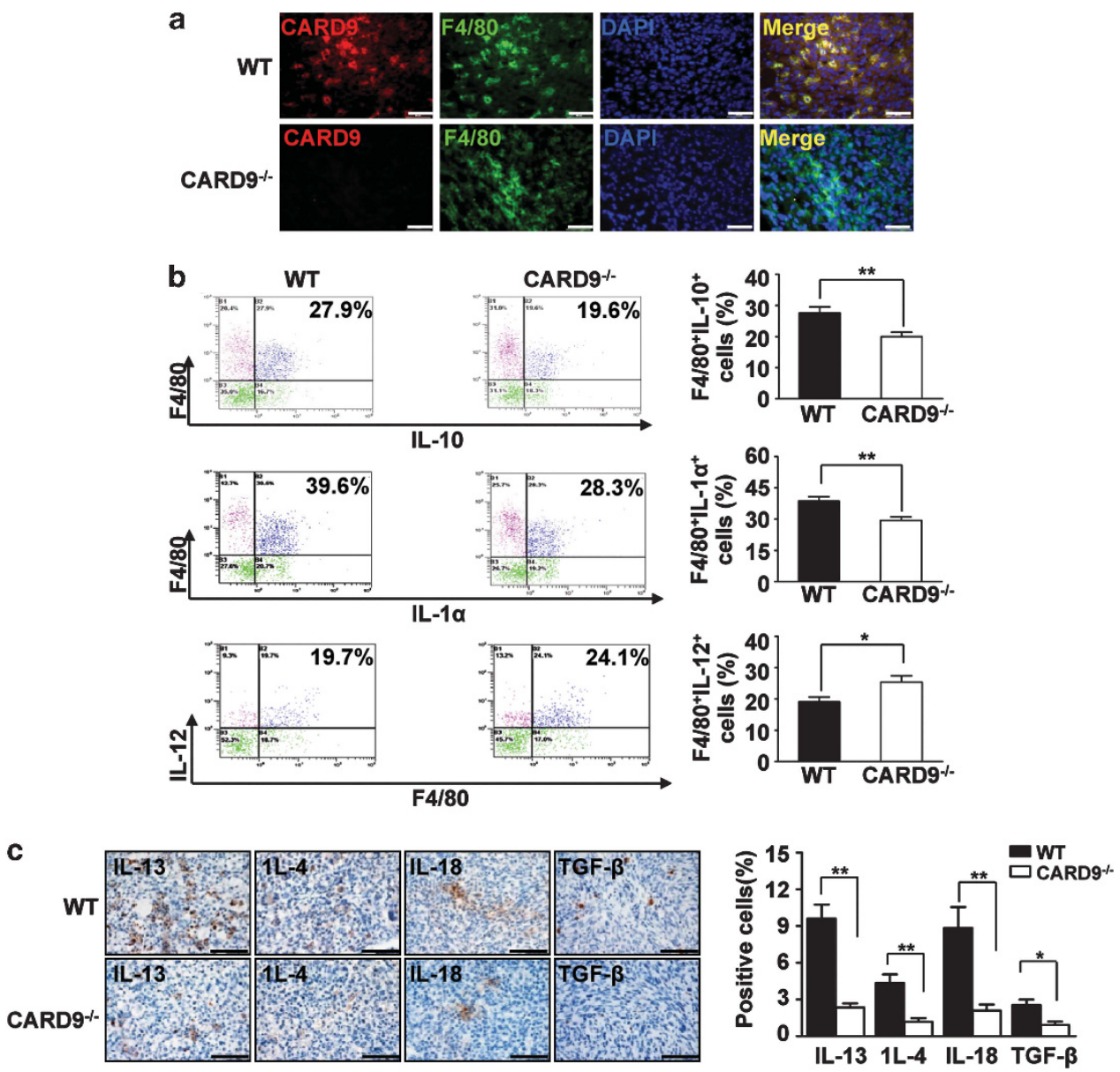

Figure 4 CARD9 deficiency reduces tumor-promoting cytokine expression in tumor development. (a) Double immunofluorescence analysis of macrophage marker F4/80 and CARD9 expression in metastatic foci from WT and CARD9 ${ }^{-1}$ - mice. The sections were stained with anti-F4/80 (green) or anti- CARD9 (red) antibody and DAPI (blue; to stain the nuclei). Scale bars $=50 \mu \mathrm{m}$. (b) Intracellular cytokines IL-10, IL-1 $\alpha$ and IL-12 were detected by flow cytometry from metastatic foci in the liver after intrasplenic injection of colon SL4 cells in WT and CARD9 ${ }^{-1-}$ mice. Data are mean \pm S.E.M. for $n=8$ mice per group animal. ${ }^{*} P<0.05,{ }^{* *} P<0.01$ versus WT mice. (c) Immunohistochemical analysis of cytokine expression after intrasplenic injection of SL4 cells in WT and CARD9- ${ }^{-1}$ mice. Cytokine expression detected by anti-IL-13, anti-IL-4, anti-IL-18 and anti-TGF- $\beta$ immunostaining $(\times 400$ magnification and scale bars $=50 \mu \mathrm{m})$. Quantitative analysis of cytokine expression in metastasized foci sections. Data are mean \pm S.E.M. for $n=8$ mice with 10 fields per animal. ${ }^{*} P<0.05,{ }^{\star *} P<0.01$ versus WT mice

markedly and extensively infiltrated in poorly differentiated colon carcinoma tissues. Importantly, CD206, a marker of M2 macrophages, was abundantly expressed in the area where CD68-positive macrophages were also located in poorly differentiated tumor tissues (Figure 5a). In well differentiated or moderately differentiated tumor tissue, the number of CD206-positive cells was significantly reduced compared with poorly differentiated tumor tissues (Figure 5a). The clinicopathologic analysis indicated no apparent relationship between the level of CARD9 and gender, age or tumor size (Table 1). However, a negative correlation between CARD9 level and tumor differentiation was observed $(P<0.0001$; Table 1$)$. A positive immunohistochemical reaction for CARD9 was more frequently observed in poorly differentiated tumors $(16.01 \pm 1.54 \%)$ compared with moderately differentiated $(6.44 \pm 0.52 \%)$ and well differentiated $(1.04 \pm 0.28 \%)$ tumors (Table 1). Moreover, CARD9 expression was positively correlated with tumor invasion depth $(P=0.02)$ and metastasis $(P<0.0001$; Table 1$)$.
Flow cytometric analysis showed the population of macrophages in hepatic metastatic tumors of WT mice was predominantly CD206-positive, but the proportion of $\mathrm{M} 2$ macrophages $\left(\mathrm{CD} 45^{+} \mathrm{F} 4 / 80^{+} \mathrm{CD} 206^{+}\right.$cells) was significantly reduced in the metastatic foci of CARD9 ${ }^{-1-}$ mice. Moreover, immunofluorescence analysis showed significantly fewer double-positive $F 4 / 80 / C D 206$ viable macrophages in the metastatic foci of CARD9 $^{-1-}$ mice than that in WT mice (Figure 5c). Moreover, CARD9 ${ }^{-1-}$ or WT BMDMs cocultured with SL4 cells showed no morphologic differences (Supplementary Figure 4), but two-color immunofluorescence analysis revealed that CD206 expression was significantly higher in WT BMDMs than CARD9 ${ }^{-1-}$ BMDMs cocultured with SL4 cells (Figure $5 d$ ). These results suggest that CARD9 may mediate protumor immune responses by polarizing macrophages toward the metastasis-promoting phenotype.

CARD9 polarizes macrophages toward a metastasispromoting phenotype in the tumor microenvironment through activation of NF- $\kappa \mathrm{B}$ signaling. As shown in 
a

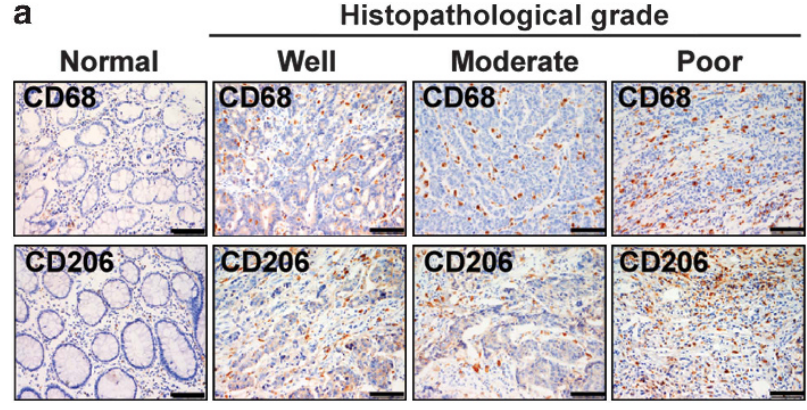

b

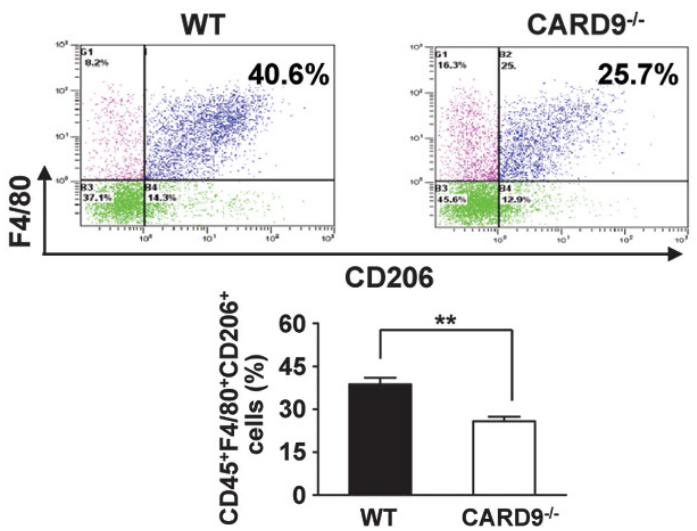

C
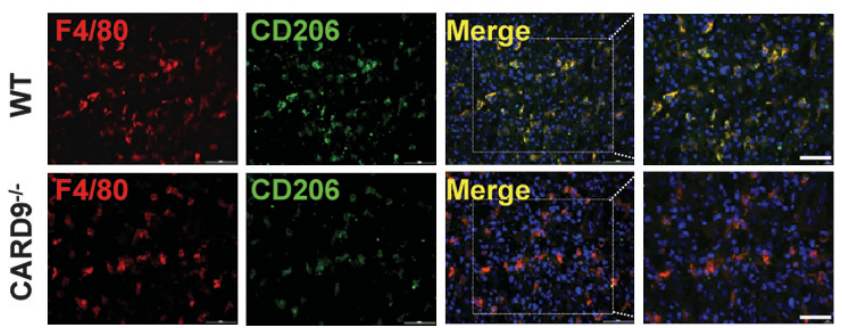

d
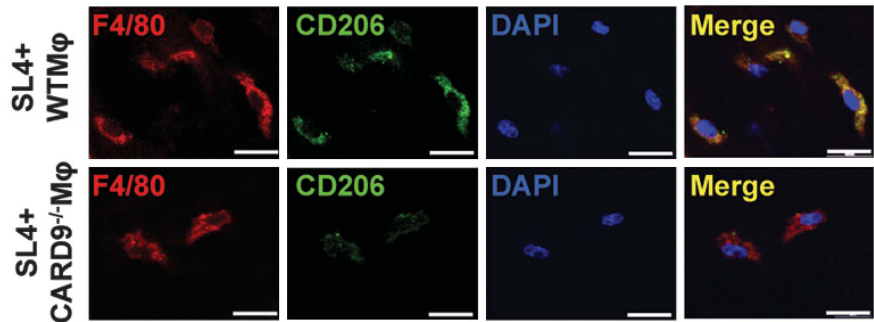

Figure 5 Tumor cell-educated macrophages promote tumor metastasis is mediated by CARD9. (a) Immunohistochemical analysis of CD68 and CD206 expression in different histopathological grades of colon carcinoma tissue and adjacent normal colon tissues ( $\times 200$ magnification and scale bars $=100 \mu \mathrm{m}$ ). (b) Leukocytes were gated with CD45 fluorescence, macrophage M2 marker $\left(\mathrm{CD} 45^{+} \mathrm{F} 4 / 80^{+} \mathrm{CD} 206^{+}\right)$were detected by flow from metastatic foci in the liver after intrasplenic injection of SL4 cells in WT and CARD9 ${ }^{-1-}$ mice. Data are mean \pm S.E.M. for $n=8$ mice per group. ${ }^{* *} P<0.01$ versus WT mice. (c) Double immunofluorescence analysis of M2 macrophage expression in metastatic foci from WT and CARD9 ${ }^{-1-}$ mice. The sections were immunostained using the combination of anti-F4/80 (red) or anti-CD206 (green) antibodies and DAPI (blue; to stain the nuclei). Scale bars $=50 \mu \mathrm{m}$. (d) WT or CARD9 ${ }^{-1}$ - BMDMs were cocultured with SL4 cells in nano gels and then double-color immunofluorescence analysis of macrophage phenotype by stained with F4/80 and CD206 antibodies. Scale bars $=10 \mu \mathrm{m}$

Figure 6a, p65 was localized primarily in the nucleus of F4/80-positive macrophages in hepatic metastatic tumors of WT mice but primarily in the cytoplasm of macrophages in CARD $^{-1-}$ mice. Western blot analysis showed that phosphorylation of $\mathrm{p} 65$, the inhibitory protein IKK $\alpha / \beta$ (inhibitor of $\kappa \mathrm{B}$ kinase $\alpha / \beta$ ) or $\mathrm{l}-\kappa \mathrm{B} \alpha$ (inhibitor of $\kappa \mathrm{B} \alpha$ ) was markedly decreased in the metastatic foci of $\mathrm{CARD}^{-1-}$ mice compared with that in WT mice (Figure 6b). Moreover, CARD9 $^{-1-}$ BMDMs showed a marked decrease in p65 phosphorylation, and also significantly lower phosphorylation of $\mathrm{IKK} \alpha / \beta$ and $\mathrm{I}-\kappa \mathrm{B} \alpha$ than WT BMDMs following coculture with SL4 cells (Figure 6c). We further evaluated the effect of CARD9 on NF- $\kappa$ B transcriptional activity of macrophages by luciferase-promoter assay. CARD9 ${ }^{-1-}$ or WT BMDMs did not differ in basal NF- $\kappa$ B activity, but SL4 cell coculture induced a significant increase in $\mathrm{NF}-\kappa \mathrm{B}$ activity in WT BMDMs compared with CARD9 ${ }^{-/-}$BMDMs (Figure 6d).

To further confirm that CARD9 has an important role in macrophage polarization via the NF- $\kappa$ B pathway, p65-specific siRNA was used to knock down endogenous p65 expression in WT BMDMs, and we assayed the metastasis-promoting phenotype of BMDMs using SL4 cell coculture. As shown in Figure 6e, p65-specific siRNA markedly attenuated mRNA levels of VEGFR1, TGF- $\beta$ and IL-1 $\beta$ (prometastatic markers) in WT BMDMs cocultured with SL4 cells. Moreover, p65 siRNA-transfected BMDMs expressed lower levels of tumor-promoting cytokines $\mathrm{IL}-10$ and $\mathrm{IL}-1 \alpha$ mRNA, but a higher level of antitumor cytokine IL-12p40 mRNA than control siRNA-transfected BMDMs after coculture with SL4 cells (Supplementary Figure 5). Taken together, these results provide evidence for a novel role of CARD9 in programming macrophages toward the metastasis-promoting phenotype by activation of NF- $\kappa \mathrm{B}$ signaling.

Syk activation is necessary for CARD9-BCL10-MALT1 complex formation contributing to tumor cell-driven metastasis-associated macrophage polarization. We examined whether activation of spleen tyrosine kinase (Syk) in RAW 264.7 cells is independent of physical contact with SL4 cells. Coculture with SL4 cells for 6-, 12-, 18- or 24-h induced Syk phosphorylation in a time-dependent manner (Figure 7a). Furthermore, double immunofluorescence analysis demonstrated that the level of Syk phosphorylation was elevated in RAW 264.7 cells after coculture with SL4 cells, but was lower in the control RAW 264.7 cells (Figure 7b). Similarly, there was marked Syk phosphorylation on Tyr525/526 and Tyr323 in WT BMDMs at $12 \mathrm{~h}$ with SL4 cells treatment; maximal effects on Tyr352/319, Tyr525/526 and Tyr323 Syk phosphorylation were observed at $24 \mathrm{~h}$ (Figure 7c).

Western blot analysis showed that levels of CARD9, B-cell lymphoma/leukemia 10 (BCL10) and mucosa-associated lymphoid tissue lymphoma translocation protein 1 (MALT1) 
Table 1 Clinicopathological parameters and the expression of CARD9 in human colon carcinoma

\begin{tabular}{|c|c|c|c|}
\hline Factors & Number & CARD9 level (\%) & $P$-value \\
\hline \multicolumn{4}{|l|}{ Age (years) } \\
\hline$<50$ & 13 & $9.29 \pm 1.63$ & \multirow[t]{2}{*}{0.86} \\
\hline$\geq 50$ & 35 & $8.87 \pm 1.46$ & \\
\hline \multicolumn{4}{|l|}{ Gender } \\
\hline Male & 26 & $8.72 \pm 1.25$ & \multirow[t]{2}{*}{0.78} \\
\hline Female & 22 & $8.19 \pm 1.36$ & \\
\hline \multicolumn{4}{|l|}{ Size } \\
\hline$<5 \mathrm{~cm}$ in diameter & 30 & $7.69 \pm 1.05$ & \multirow[t]{2}{*}{0.25} \\
\hline$\geq 5 \mathrm{~cm}$ in diameter & 18 & $9.91 \pm 1.71$ & \\
\hline \multicolumn{4}{|l|}{ Differentiation } \\
\hline Well & 7 & $1.04 \pm 0.28$ & \multirow[t]{3}{*}{$<0.0001$} \\
\hline Moderately & 29 & $6.44 \pm 0.52$ & \\
\hline Poorly & 12 & $16.01 \pm 1.54$ & \\
\hline \multicolumn{4}{|l|}{ Invasion } \\
\hline $\mathrm{T} 1$ & 2 & $1.52 \pm 0.80$ & \multirow[t]{4}{*}{0.02} \\
\hline $\mathrm{T} 2$ & 6 & $3.35 \pm 1.40$ & \\
\hline T3 & 31 & $8.98 \pm 0.95$ & \\
\hline $\mathrm{T} 4$ & 9 & $12.41 \pm 2.94$ & \\
\hline \multicolumn{4}{|l|}{ Nodal status } \\
\hline NO & 27 & $5.29 \pm 0.89$ & \multirow[t]{2}{*}{$<0.0001$} \\
\hline $\mathrm{N} 1-\mathrm{N} 2$ & 21 & $12.48 \pm 1.34$ & \\
\hline \multicolumn{4}{|l|}{ Distant metastasis } \\
\hline MO & 45 & $7.34 \pm 0.75$ & \multirow[t]{2}{*}{$<0.0001$} \\
\hline M1 & 3 & $23.05 \pm 3.60$ & \\
\hline \multicolumn{4}{|l|}{ Recurrence } \\
\hline No & 40 & $6.64 \pm 0.62$ & \multirow[t]{2}{*}{$<0.0001$} \\
\hline Yes & 8 & $18.97 \pm 2.09$ & \\
\hline
\end{tabular}

Correlation of CARD9 expression levels and clinicopathological characteristics in colon carcinoma. Histopathological differentiation grade indicates well differentiated, moderately differentiated and poorly differentiated. T indicates tumor invasion depth. $\mathrm{N}$ indicates lymph node metastasis. $\mathrm{M}$ indicates distant metastasis. Human CARD9 expression measurements at different histopathologic grades and tumor invasion depth of colon carcinoma were analyzed by one-way ANOVA test among groups. The levels of CARD9 based on gender, age, tumor size, metastatic status and recurrence of human colon carcinoma were analyzed with the unpaired Student's $t$-test

did not differ in RAW 264.7 cells with or without SL4 cell coculture (Figure 7d). To further determine whether the inducible formation of the CARD9-BCL10-MALT1 complex is dependent on Syk activation, we used the Syk-selective inhibitor piceatannol. We found that CARD9 formed a complex with BCL10 and MALT1 following SL4 cell coculture (Figure 7d). However, piceatannol treatment of RAW 264.7 cells led to attenuation of SL4 cell-induced CARD9-BCL10MALT1 association (Figure 7d).

To confirm that the Syk-CARD9-dependent signaling pathway has an important role in macrophage polarization in the tumor microenvironment, we treated WT or CARD9 ${ }^{-1-}$ BMDMs with the Syk inhibitor before coculture with SL4 cells. Syk inhibitor piceatannol or BAY61-3606 significantly suppressed M2 markers including chemokine (C-C motif) ligand 22 (CCL22), CCL17 and YM1 mRNA, but elevated several M1 markers such as IL-12p40 and inducible nitric oxide synthase (iNOS) mRNA in WT BMDMs cocultured with SL4 cells (Figure 7e). Similar findings were obtained when analyzing M2- or M1-associated genes in $\mathrm{CARD9}^{-1-}$ BMDMs compared with WT BMDMs cocultured with SL4 cells (Figure 7e). However, piceatannol or BAY61-3606 treatment did not further affect the M2 or M1 profile of CARD9 ${ }^{-1-}$ BMDMs (Figure 7e). Moreover, RAW 264.7 cells treated with piceatannol or BAY61-3606 expressed lower levels of the M2 genes CCL22, CCL17 and YM1, but expressed higher levels of the M1 genes IL-12p40 and chemokine (C-X-C motif) ligand 9 (CXCL9) with SL4 cell coculture (Supplementary Figure 6). Overall, Syk has an important role in inducing the assembly of the CARD9-BCL10-MALT1 complex and subsequently driving macrophages toward the metastasis-promoting phenotype.

Tumor cell-secreted VEGF facilitates Syk activation in macrophages. We next sought to identify the cytokines secreted by tumor cells that can activate the Syk-CARD9dependent signaling pathway in macrophages. The cytokines in supernatants from SL4 cells and WT BMDMs as a control were analyzed by Bio-Plex array assay. As shown in Figure 8a, comparison of the cytokine profile identified VEGF as the most highly expressed cytokine in the supernatants of SL4 cells. In addition, supernatants from SL4 cells showed moderate amounts of IL-15 and monokine-induced by gamma interferon (MIG) compared with WT BMDMs, and small amounts of IL-18, platelet-derived growth factor-BB and leukemia inhibitory factor, but not other cytokines such as fibroblast growth factors or macrophage inflammatory proteins-2 (Figure 8a). To further determine which tumor cell-secreted cytokine is necessary for inducing Syk activity in macrophages, we used specific neutralizing antibodies against the identified cytokines. As shown in Figure 8b, VEGF inhibition displayed a striking decrease in Syk phosphorylation of WT BMDMs cocultured with SL4 cells, whereas neutralization of IL-15 or MIG did not inhibit SL4 cell-induced Syk phosphorylation in WT BMDMs. Thus, VEGF is a key cytokine secreted by cancer cells that stimulates macrophage Syk activity in a paracrine manner.

\section{Discussion}

Accumulating evidence suggests that the invasive behavior of tumor cells depends on crosstalk between tumor and host cells in a complex microenvironment. ${ }^{19,20}$ It was previously demonstrated that, at metastatic sites, a distinct population of metastasis-associated macrophages promotes the extravasation, seeding and persistent growth of tumor cells. ${ }^{13,21}$ CARD9, an adaptor protein of innate immune responses, has been found to have a prominent role in the pathogenesis of immune responses and inflammatory disorders, but the potential association between CARD9 expression and tumor metastasis has not been explored. In this study, we identified CARD9 as being overexpressed in human primary colon cancer relative to normal colon tissue and provide the first evidence of the high concordance of CARD9 expression and macrophage infiltration. In metastatic lymph nodes, histological analysis showed that high CARD9 expression was significantly associated with increased macrophage infiltration and poorly differentiated metastasis. The clinicopathologic analysis suggests a strong correlation between 

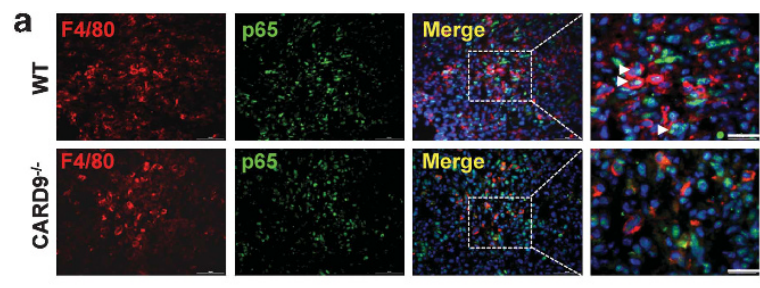

b
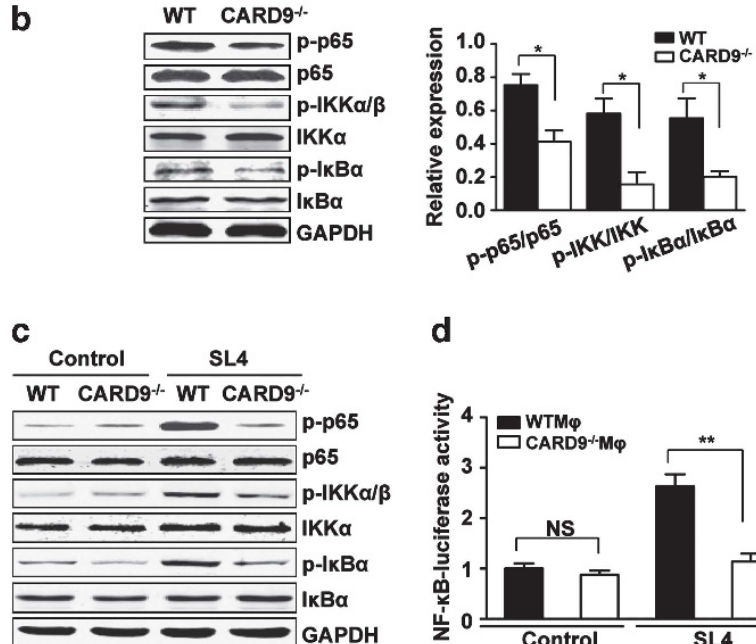

d

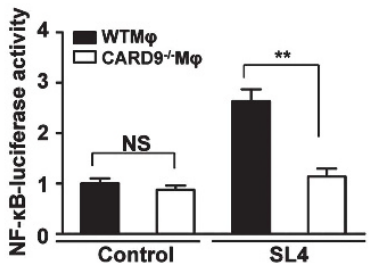

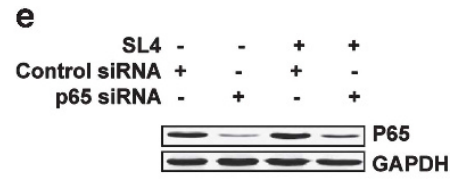
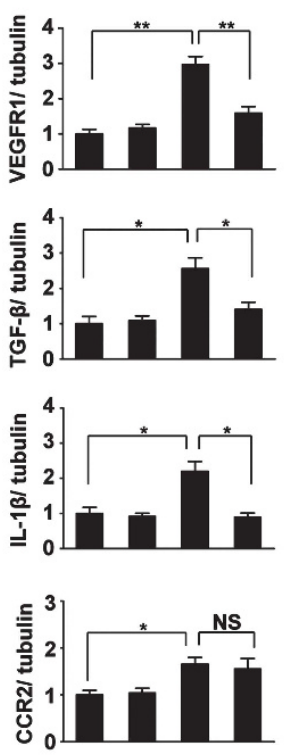

Figure 6 Metastasis-associated macrophages polarization by CARD9 relies on NF- $\kappa$ B activation. (a) Double immunofluorescence analysis of NF- $\kappa$ B activation of macrophages after intrasplenic injection of SL4 cells in WT and CARD ${ }^{-1-}$ mice. The sections were immunostained using the combination of anti-F4/80 (red) or anti-p65 (green) antibodies and DAPI (blue; to stain the nuclei). Scale bars $=20 \mu \mathrm{m}$. (b) The phosphorylation levels of $\mathrm{p} 65,|\mathrm{KK} \alpha / \beta,| \kappa B \alpha$ in metastatic foci were measured by western blotting. Metastatic foci in the liver were obtained from WT and CARD ${ }^{-1-}$ mice at 14 days after intrasplenic SL4 cells injection. Data are mean \pm S.E.M. for $n=5$ mice per group. ${ }^{*} P<0.05$. (c) WT or CARD9 ${ }^{-1-}$ BMDMs were cocultured with SL4 cells using a transwell system for $48 \mathrm{~h}$. Western blot analysis of the phosphorylation levels of p65, IKK $\alpha / \beta$, I $\kappa B \alpha$ in WT or CARD $^{-1-}$ BMDMs by SL4 cell coculture. GAPDH was used as a loading control. Three independent experiments were performed. (d) The effect of CARD9 expression on NF- $\kappa$ B activation of macrophages using a luciferase-promoter assay in three-dimensional (3-D) coculture. WT and CARD9- ${ }^{-}$BMDMs were transiently transfected with adenovirus $\mathrm{NF}-\kappa \mathrm{B}-\mathrm{luc}$, then cocultured with SL4 cells in 3-D nano gels. Luciferase activity was measured by a luminometer. Data are mean \pm S.E.M. of three independent experiments. ${ }^{* *} P<0.01$. (e) Effect of p65 small interfering RNA (siRNA) on macrophage polarization in transwell coculture system. WT BMDMs were transiently transfected with p65-specific or control siRNA, and then cocultured with SL4 cells for $48 \mathrm{~h}$. Western blot analysis was used to verify siRNA-mediated p65 knockdown in BMDMs. Quantitative real-time PCR analysis of the mRNA expression of VEGFR1, TGF- $\beta$, IL-1 $\beta$ and C-C motif chemokine receptor 2 (CCR2; cell markers of metastasis-associated macrophages). Tubulin was a normalization control. Data are mean \pm S.E.M. of three independent experiments. ${ }^{*} P<0.05$, ${ }^{*} P<0.01$, NS indicates not significant

CARD9 and signs of tumor progression such as histologic grade, tumor stage, metastasis and recurrence, further supporting its potential to foster the development of tumor metastasis. Thus, this study provides new insights into this area of research by identifying CARD9 as a clinically relevant promoter of tumor metastasis. Histological analysis, bioluminescence imaging and the BM transplantation experiments revealed that the expression of CARD9 by BM-derived leukocytes, upon infiltration into the tumor microenvironment, has a pivotal role in cancer metastasis in vivo. Notably, these findings uncover a novel molecular mechanism of the CARD9dependent signaling pathway, which may prove clinically useful for developing a new prognostic biomarker and therapeutic target for tumor metastasis.

Increased infiltration of tumor-associated macrophages (TAMs) is correlated with a poorer survival rate and a worse prognosis for most solid tumors such as papillary thyroid carcinoma, ${ }^{22}$ breast cancer, ${ }^{23}$ endometrial cancer, ${ }^{8}$ colorectal cancer $^{24}$ and gastric cancer. $^{25}$ Interestingly, CARD9 deficiency did not affect the proportion of macrophages, $\mathrm{CD}^{+}{ }^{+}$or $\mathrm{CD}^{+}{ }^{+} \mathrm{T}$ lymphocytes in hepatic metastatic tumors. Our findings suggest that CARD9 deficiency could block tumor metastasis through different mechanisms to promote macrophage function in the tumor microenvironment, independent of the number of infiltrating macrophages.

TAMs have an M2-like phenotype and result in invasion and metastasis. M2-polarized macrophages produce lower levels of proinflammatory cytokines, such as tumor necrosis factoralpha and IL-12, and higher levels of immunosuppressive mediators, such as IL-10, TGF- $\beta$ and VEGF. ${ }^{4,26}$ On the other hand, tumor cells can profoundly affect macrophage function. Tumor cells shape their interaction with macrophages by escaping phagocytosis ${ }^{27}$ and promoting M2-like polarization via chemokines, polarizing cytokines and selective autophagy. ${ }^{28-31}$ The results obtained from our in vitro coculture of SL4 cells with WT or CARD9 ${ }^{-1-}$ BMDMs were consistent $^{-1}$ with our in vivo findings of the expression of cytokines or prometastatic genes in infiltrating macrophages. The findings demonstrated that CARD9 is responsible for driving macrophages toward the metastasis-promoting phenotype in the tumor microenvironment, contributing to tumor metastasis. These results are in agreement with a recent report indicating that $\mathrm{CD}^{+}{ }^{+} \mathrm{T}$ lymphocytes do not regulate leukocyte infiltration, but instead regulate the bioeffector function of myeloid cell subsets. ${ }^{32}$ Taken together, these observations suggest that immune or tumor cells can participate in the orchestration 

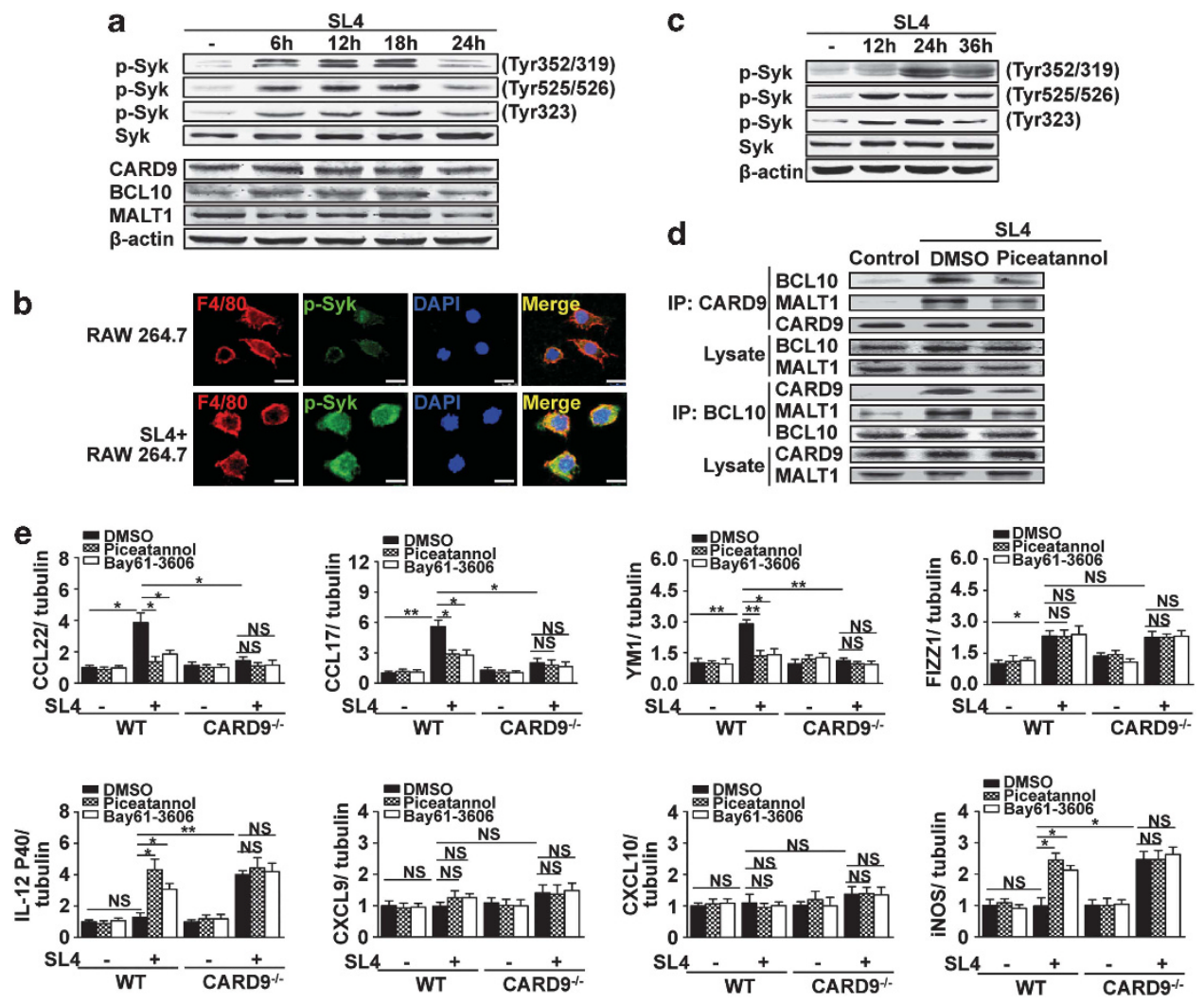

Figure 7 Syk activation by SL4 cells is necessary for CARD9-BCL10-MALT1 complex formation contributing to tumor cell-driven metastasis-associated macrophages. (a) RAW264.7 cells were cocultured with SL4 cells using a transwell system for the indicated times, and representative blots of p-Syk, total Syk and CARD9, BCL10, MALT1 are shown. $\beta$-Actin was used as a loading control. (b) Double immunofluorescence analysis of Syk activation of RAW264.7 cells (anti-F4/80) with or without SL4 cells treatment for $18 \mathrm{~h}$. RAW264.7 cells were immunostained using the combination of anti-F4/80 (red) or anti-p-Syk (green) antibodies and DAPI (blue; to stain the nuclei). Scale bars $=5 \mu \mathrm{m}$. (c) WT BMDMs were cocultured with SL4 cells using a transwell system for the indicated times. Western blot analysis of the phosphorylation levels of Syk in WT BMDMs by SL4 cell coculture. $\beta$-Actin was used as a loading control. (d) Syk inhibitor (piceatannol) impairs formation of the CARD9-BCL10-MALT1 complex in RAW264.7 cells with SL4 cell coculture. RAW264.7 cells were pretreated with $50 \mu \mathrm{mol} / /$ piceatannol or DMSO (vehicle) and then subjected to SL 4 cell coculture for $18 \mathrm{~h}$. The cell lysates were immunoprecipitated (IP) with anti-CARD9 or anti-BCL10 antibodies and probed with anti-BCL10, anti-MALT1 and CARD9 antibodies. (e) WT or CARD9 ${ }^{-1-}$ BMDMs were pretreated with $50 \mu \mathrm{mol} / /$ piceatannol or BAY 61-3606 (Syk inhibitor) or DMSO (vehicle) and then subjected to SL4 cell coculture for $24 \mathrm{~h}$. Quantitative real-time PCR analysis of the mRNA expression of M2 marker (CCL17, CCL22, FIZZ1 and YM1) or M1 marker (IL-12p40, CXCL9, CXCL10 and iNOS). Tubulin was a normalization control. Data are mean \pm S.E.M. of three independent experiments. ${ }^{*} P<0.05,{ }^{*} P<0.01$. NS indicates not significant

of macrophage function via the secretion of cytokines, growth factors and immune complexes. Future study is warranted to fully understand the importance of this interaction in vivo.

Recent studies demonstrated that inhibition of the IKK $\beta / N F-\kappa B$ pathway may promote antitumor polarization of macrophages, whereas retaining IKK $\beta / \mathrm{NF}-\kappa \mathrm{B}$ activation maintains these cells in a tumor-promoting activation state. ${ }^{33}$ CARD9 is expressed in myeloid cells, where it operates as a key mediator of $\mathrm{NF}-\kappa \mathrm{B}$ activation in innate anti-fungal immunity. ${ }^{16,34,35}$ Our findings indicate that NF- $k$ B signaling could be the downstream pathway for CARD9-mediated metastasis-associated macrophage polarization. These results are consistent with the finding that NF- $\kappa \mathrm{B}$ activation would support an anti-inflammatory, immunosuppressive M2 phenotype in a mouse model of ovarian cancer as suggested by Hagemann et al. ${ }^{33}$

CARD9 was recently shown to be a key integrator of immune responses, which leads to downstream formation of a signaling complex of CARD9 with other adaptor proteins, particularly BCL10 and MALT1, and activation of NF- $\kappa$ B and MAPK. ${ }^{16,34}$ Our data demonstrated that CARD9, the central adaptor protein, is involved in polarizing macrophages toward the metastasis-promoting phenotype within the tumor microenvironment. However, it is unknown how tumor cells drive the CARD9-dependent signaling pathway in macrophages. Syk is a key intracellular kinase, which acts through its immunoreceptor tyrosine-based activation-like motif to trigger several intracellular signaling cascades, leading to induction of various cytokines. ${ }^{36}$ Our findings suggest that SL4 cells trigger Syk activation, leading to the formation of the CARD9-BCL10-MALT1 complex that mediates metastasisassociated macrophage polarization. Our results further elucidated that SL4 cell-secreted VEGF is both necessary and sufficient for activation of Syk in macrophages. Indeed, several reports demonstrated that tumor cell-secreted VEGF-C not only promotes tumor cell invasion by autocrine mechanisms, to make tumor cells more proteolytic and migratory, but also enhances chemoattraction of tumor cells toward the lymphatics by paracrine signaling mechanisms. ${ }^{37}$ Thus, we propose that tumor cell-secreted VEGF is a key cytokine that induces Syk activity in macrophages, indicating a novel function for this cytokine 


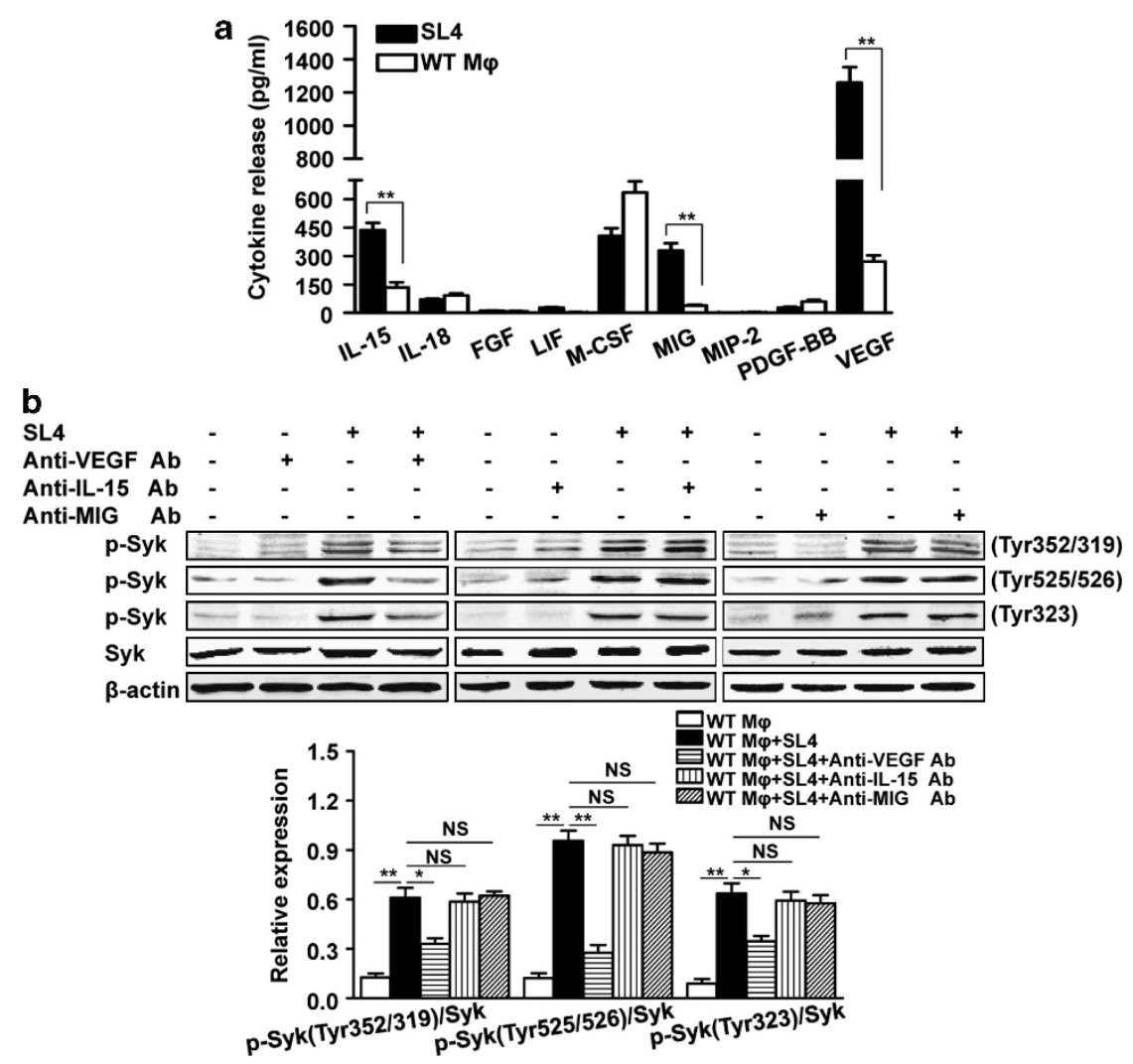

Figure 8 Tumor cell-secreted VEGF mediates Syk activation in macrophages. (a) Cytokines released into culture supernatants from SL4 cells or WT BMDMs were determined using Bio-Plex Cytokine Assay Kits (Bio-Rad Laboratories). Data are mean \pm S.E.M. of three independent experiments. ${ }^{* *} P<0.01$. (b) Specific neutralizing Abs against VEGF, but not IL-15 and MIG, significantly blocked the phosphorylation levels of Syk in macrophages by SL4 cell coculture. WT BMDMs were preincubated with anti-VEGF Ab, anti-IL-15 Ab or anti-MIG Ab for $2 \mathrm{~h}$ before coculturing with SL4 cells. Western blot analysis of the phosphorylation levels of Syk in WT BMDMs. $\beta$-Actin was used as a loading control. Data are mean \pm S.E.M. of three independent experiments. ${ }^{*} P<0.05,{ }^{\star \star} P<0.01$. NS indicates not significant

by influencing the specific immune cell populations in the tumor microenvironment.

In conclusion, we have identified a novel role of BM-derived CARD9 that can contribute to tumor metastasis, which is associated with worse clinicopathologic parameters and poor cancer prognosis via regulation of metastasis-associated macrophages. In the tumor microenvironment, tumor cellsecreted VEGF facilitates activation of the Syk signaling pathway in macrophages, leading to induction of the assembly of the CARD9-BCL10-MALT1 complex. CARD9 primes macrophages toward metastasis-promoting polarization by activating the NF- $\kappa \mathrm{B}$ pathway. Together with clinical and experimental findings, we propose CARD9 as a new target for cancer therapy, and further studies of the mechanisms regulating metastasis-associated macrophages could provide novel insights into understanding how the tumor microenvironment modulates tumor progression.

\section{Materials and Methods}

Antibodies and reagents. The antibodies for CARD9, CD206, CD68, TGF- $\beta$, IL-13, IL-4, IL-18, BCL10, MALT1, GAPDH, $\beta$-actin and IgG were from Santa Cruz Biotechnology (Santa Cruz, CA, USA), the phospho-Syk antibody sampler kit, NF- $\kappa$ B pathway sampler kit were from Cell Signaling Technology (Beverly, MA, USA); the antibody for F4/80 was from Abcam (Cambridge, MA USA); and ChemMate TM EnVision System/DAB Detection Kits were from Dako (Glostrup, Denmark). Antibodies for PerCP/Cy5.5-conjugated CD45.2, phycoerythrin (PE)-conjugated $\mathrm{F} 4 / 80$, fluorescein isothiocyanate (FITC)-conjugated $\mathrm{F} 4 / 80$,
FITC-conjugated CD206, PE-conjugated CD3, FITC-conjugated CD4, FITC-conjugated CD8 and isotype control were from Biolegend (San Diego, CA, USA). FITC-conjugated IL-10, FITC-conjugated IL-1 $\alpha$ and PE-conjugated IL-12 were from eBioscience (San Diego, CA, USA). Piceatannol and BAY61-3606 were from Sigma (St. Louis, MO, USA). Bio-Plex Cytokine Assay Kits were from Bio-Rad Laboratories (Hercules, CA, USA). Neutralizing anti-VEGF Ab and anti-MIG Ab were from R\&D Systems (Minneapolis, MN, USA). Neutralizing anti-IL-15 Ab was from Abcam.

Animals. The $\mathrm{CARD}^{-1-}$ mouse strain was backcrossed onto the genetic background of C57BL/6 for $>10$ generations, was kindly provided by Dr. Xin Lin from The University of Texas MD Anderson Cancer Center, Houston, TX, USA. Mice were 8-12 weeks old at the beginning of the experiments, matched for age and sex with WT mice, and kept under specific pathogen-free conditions at the Beijing Anzhen Hospital affiliated to Capital Medical University, China. All animal care and experimental protocols complied with the Animal Management Rule of the Ministry of Health, People's Republic of China (documentation no. 55, 2001) and the Guide for the Care and Use of Laboratory Animals published by the US National Institutes of Health (NIH publication no. 85-23, revised 1996) and were approved by the Institutional Animal Care and Use and Committee of Capital Medical University.

Tumor model. SL4 cells are colon cancer cells ${ }^{38}$ derived from C57BL/6 mice on the same background as the CARD ${ }^{-1-}$ mice and WT control mice. SL4 cells were maintained in DMEM/F12 culture medium, supplemented with $10 \%$ FBS in a humidified $37^{\circ} \mathrm{C}$ incubator under $5 \% \mathrm{CO}_{2}$. For in vivo hepatic metastasis model, after anesthetizing mice, a transverse incision in the left flank was made, exposing the spleen, then $1.0 \times 10^{6} \mathrm{SL} 4$ tumor cells in $100 \mu \mathrm{l}$ DMEM/F12 medium were intrasplenically injected with use of a 26 -gauge needle. Fourteen days after inoculation, mice were killed, and the tissues were processed as described below. The liver weights were measured, and the incidence of liver metastasis was examined. 
In vivo bioluminescence imaging. SL4-Luc murine colon cancer cells stably expressing firefly luciferase $\left(1.0 \times 10^{6}\right)$ were suspended in $100 \mu \mathrm{l}$ DMEM/ F12 medium and implanted into the spleens of C57BL/6 or CARD9 ${ }^{-1-}$ mice (C57BL/6 backgrounds) under anesthesia. Bioluminescence from the luciferaseexpressing SL4 cells was determined at days 3, 7, 10 and 14 postinjection, using the Xenogen IVIS Lumina System coupled to Livinglmage data-acquisition software (Xenogen Corp., Alameda, CA, USA). Mice were anesthetized by isoflurane ( $2 \%$ vaporized in $\mathrm{O}_{2}$ ) and imaged $10 \mathrm{~min}$ after intraperitoneal injection of D-luciferin solution $(150 \mathrm{mg} / \mathrm{kg}$, Caliper Life Sciences, Alameda, CA, USA). Bioluminescence intensity plots were quantified as photon flux $\left(\mathrm{p} / \mathrm{s} / \mathrm{cm}^{2} / \mathrm{sr}\right)$ using Livinglmage software (Xenogen Corp.).

BM transplantation. The transplantation procedure was performed as described previously. ${ }^{39}$ Briefly, donor BM cells were collected from 10-week-old WT and CARD ${ }^{-1-}$ mice by flushing humerus, femurs and tibiae with DMEM medium. Ten-week-old recipient mice were lethally irradiated with a dose of $10 \mathrm{~Gy}$ $(1000 \mathrm{rad})$. Approximately $4 \mathrm{~h}$ after irradiation, $1 \times 10^{7} \mathrm{BM}$ donor cells were transplanted to recipient mice by orbital plexus injection. Mice recovered for 8 weeks to ensure stable engraftment of the donor BM cells. BM chimerism was determined in genomic DNA from BM and used for genotyping with PCR analysis. BM cells were transplanted to generate (1) $\left(\mathrm{WT}_{\mathrm{BM}} \rightarrow \mathrm{WT}\right)$, (2) $\left(\mathrm{CARD}^{-1-}{ }_{\mathrm{BM}} \rightarrow\right.$ $\mathrm{CARD9}^{-1-}$ ) mice as controls, (3) (CARD9 $\left.{ }^{-1-} \mathrm{BM} \rightarrow \mathrm{WT}\right)$ and (4) $\mathrm{CWT}_{\mathrm{BM}} \rightarrow$ CARD $^{-1-}$ ) chimeric mice. A small group of irradiated control mice that were injected with cell-free vehicle did not survive beyond 2 weeks after irradiation. BM transplant recipient mice were subjected to SL4 injection as described above.

Human colon carcinoma specimens. The specimens from 48 cases of human colon carcinoma tissue/adjacent normal colon tissues, 30 cases of metastatic to regional lymph nodes and the clinicopathologic data were obtained from the Second Affiliated Hospital of Nanchang University gastrointestinal tumor bank. The specimens were isolated at the time of surgery, formalin-fixed and paraffinembedded, and stained with hematoxylin and eosin, then examined by two experienced pathologists. Differentiation was assessed as described: welldifferentiated tumors possessed well-formed glands and cells with small regular nuclei and poorly differentiated tumors showed no gland formation or bizarrely shaped glands. In contrast, cells in moderately differentiated tumors were less columnar or frankly cuboidal, less polar, and contained more dysplastic nuclei than those observed in well-differentiated tumors. The clinicopathologic stage was determined according to the TNM classification system of the International Union against Cancer. RNA was extracted for fresh tissue specimens (from 10 colon carcinoma specimens and 10 adjacent normal colon tissues) with identifiable tumor in the tissue specimen. Human specimens use for research had been approved by the Second Affiliated Hospital of Nanchang University Research Ethics Committee.

Immunohistochemistry. Immunohistochemistry of paraffin sections involved the Dako ChemMate TM EnVision System (Dako) with primary antibodies for CARD9 (1:200), IL-13 (1:300), IL-4 (1:300), IL-18 (1:300), TGF- $\beta(1: 300)$, CD68 $(1: 200)$ or CD206 (1:200). Negative controls were omission of the primary antibody, goat nonimmune $\lg G$, rabbit nonimmune $\lg G$, rat nonimmune $\lg G$ or secondary antibody only; in all cases, negative controls showed insignificant staining. To verify the genotype and treatment, quantitative histology involved standard procedures, and results were confirmed by independent pathologists blinded to genotype or treatment group. Images were viewed and captured using a Nikon Labophot 2 microscope (Nikon Corp., Tokyo, Japan) equipped with a Sony CCD-IRIS/RGB color video camera (Sony Corp., Tokyo, Japan) attached to a computerized imaging system and analyzed by Image Pro Plus 3.0. (Media Cybernetics, Bethesda, MD, USA). The expression of CARD9, macrophage marker or cytokines was calculated as proportion of positive area to total tissue area for all measurements of the sections.

Frozen tumor sections $(7 \mu \mathrm{m})$ and cell slides were incubated with the primary antibodies for F4/80 (1:100), CARD9 (1:200), CD206 (1:200), p65 (1:300) and phospho-Syk $(1: 300)$ at $4{ }^{\circ} \mathrm{C}$ overnight and then with FITC- or tetramethylrhodamine isothiocyanate-conjugated secondary antibodies (Jackson ImmunoResearch Laboratories Inc., West Grove, PA, USA) at room temperature for $1 \mathrm{~h}$. Sections were viewed with a confocal laser scanning microscope (TCS 4D; Leica, Heidelberg, Germany) and a Nikon Labophot 2 microscope equipped with a Sony CCD-IRIS/RGB color video camera.

Flow cytometry. For staining of immune markers, single-cell suspensions were prepared by mechanical dispersion and enzymatic digestion of tumor tissues.
Briefly, tumor tissues were cut into multiple small cubes and digested in an enzyme mixture containing collagenase type I $(0.05 \mathrm{mg} / \mathrm{ml})$ and type IV $(0.05 \mathrm{mg} /$ $\mathrm{ml}$ ) and hyaluronidase $(0.025 \mathrm{mg} / \mathrm{ml})$, and DNase I $(0.01 \mathrm{mg} / \mathrm{ml})$ and soybean trypsin inhibitor $(0.01 \mathrm{mg} / \mathrm{ml})$ for $45 \mathrm{~min}$ at $37^{\circ} \mathrm{C}$. The cell suspension was centrifuged and preincubated with fragment crystallizable- $\gamma$ block antibody (antimouse CD16/32; PharMingen, San Diego, CA, USA) to prevent nonspecific binding. Cell staining involved different combinations of fluorochrome-coupled antibodies to CD45.2, F4/80, CD206, CD3, CD4 or CD8 for 30 min at $4{ }^{\circ} \mathrm{C}$ in the dark. For intracellular staining, cells were incubated with $50 \mathrm{ng} / \mathrm{ml} \mathrm{PMA}+1 \mu \mathrm{M}$ ionomycin in the presence of a protein transport inhibitor $\mathrm{BD}$ GolgiStop reagent (eBioscience) for $4 \mathrm{~h}$, then incubated with antibodies to IL-10, IL-1 $\alpha$ or IL-12. Fluorescence data were collected using an EPICS XL Flow Cytometer (Beckman Coulter, San Diego, CA, USA), and analyzed using CellQuest (BD Biosciences, San Jose, CA, USA). Fluorescence minus one control was included to determine the level of nonspecific staining and autofluorescence associated with subsets of cells in each fluorescence channel.

Peptide gel coculture. BMDMs were isolated from tibias and femurs of WT or CARD9 ${ }^{-1-}$ mice as previously described. ${ }^{40}$ Three-dimensional peptide gel coculture was also as described. ${ }^{40}$ BMDMs and SL4 cells were mixed at a ratio of $3: 1$ in peptide gel, then incubated at $37^{\circ} \mathrm{C}$ in a humidified atmosphere containing $5 \% \mathrm{CO}_{2}$ for $48 \mathrm{~h}$.

NF- $\kappa$ B activity assay. NF- $\kappa$ B transcriptional activity was evaluated by use of an adenovirus NF- $\kappa$ B-Luc luciferase reporter (Ad.NF- $\kappa$ B-Luc). Briefly, NF- $\kappa$ B-Luc virus-infected BMDMs were cultured in a complete growth medium for $24 \mathrm{~h}$ and cocultured with SL4 cells at a ratio of 3:1 in peptide gel. Forty-eight hours after coculture, peptide gel cultures were washed with ice-cold PBS and lysed using $150 \mu \mathrm{l}$ Passive Lysis Buffer (Promega, Madison, WI, USA), kept on ice for $30 \mathrm{~min}$, then centrifuged at 13000 r.p.m., and the supematant was stored at $-20^{\circ} \mathrm{C}$. The concentration of protein in the cell lysate was measured by the Bradford method, and an equal amount of protein from each cell lysate was assayed for luciferase activity.

P65 small interfering RNA transfection. WT BMDM suspensions ( $3 \mathrm{ml}$, $3 \times 10^{6}$ cells) were transfected with siRNA targeting mouse p65 or nonsilencing siRNA according to the manufacturer's instructions (Santa Cruz Biotechnology). At the end of siRNA transfection, SL4 cell suspensions $\left(1 \mathrm{ml}, 1 \times 10^{6}\right.$ cells) were loaded in the transwell inserts for $48 \mathrm{~h}$. BMDMs without SL4 cell inserts were used as a control in the lower compartment of the well.

Cocultures of mouse macrophage cell line, RAW 264.7 or BMDMs and tumor cells in the transwell system. Coculture systems were established by using transwell inserts $(0.4 \mathrm{~mm}$ pore, polycarbonate membrane; Costar, Cambridge, MA, USA) and transferred to six-well culture plates. The mouse macrophage cell line, RAW 264.7, was obtained from American Type Culture Collection (ATCC, Rockville, MD, USA), and cells were maintained in DMEM/F12 containing $10 \%$ FBS until confluence to cell monolayer. SL4 cell suspensions $\left(1 \mathrm{ml}, 1 \times 10^{6}\right.$ cells) were loaded in the upper inserts, and RAW 264.7 cell suspensions $\left(3 \mathrm{ml}, 3 \times 10^{6}\right.$ cells) were put into the lower compartment of the culture well and serum-starved for at least $12 \mathrm{~h}$ before coculture. Serum-free DMEM/F12 without SL4 cell inserts was used as a control in the lower compartment of the well. For Syk inhibition experiments, RAW 264.7 cells were pretreated with $50 \mu \mathrm{mol} / /$ piceatannol or BAY 61-3606 for $1 \mathrm{~h}$, followed by SL4 cell coculture for $18 \mathrm{~h}$, and controls received equivalent dilution with DMSO vehicle alone. In the same way, WT or CARD9-1- BMDMs were planted in the lower compartment of the culture well, and preincubated with $50 \mu \mathrm{mol} / /$ piceatannol or BAY 61-3606 before coculturing with SL4 cells loading in the upper inserts for $24 \mathrm{~h}$. Total cellular protein and RNA were extracted from WT or CARD9 ${ }^{-1-}$ BMDMs, RAW 264.7 cells exposed to different experimental conditions.

Immunoprecipitation and western blotting. After incubation, cells were washed twice with ice-cold PBS, and lysed in $1 \mathrm{ml}$ of lysis buffer containing $20 \mathrm{mmol} / / \mathrm{Tris}-\mathrm{HCl}$ (pH 7.4), $125 \mathrm{mmol} / / \mathrm{NaCl}, 1 \%$ Triton X-100, 1\% SDS, 2 mmol/l EDTA, $1 \mathrm{mmol} / /$ orthovanadate, $1 \mathrm{mmol} / \mathrm{l}$ benzamidine, $10 \mu \mathrm{g} / \mathrm{ml}$ aprotinin and $10 \mu \mathrm{g} / \mathrm{ml}$ leupeptin, containing protease/phosphatase inhibitor cocktail (Roche Diagnostics, Indianapolis, IN, USA). The supernatant was immunoprecipitated with respective Abs in the presence of A/G-agarose beads (Santa Cruz Biotechnology) overnight at $4{ }^{\circ} \mathrm{C}$. Beads were then pelleted, washed three times, resuspended in 
Laemmli buffer and boiled for 5 min. Protein extracts were prepared from tumor tissues, WT or CARD ${ }^{-1}$ BMDMs, RAW 264.7 cells and immunoprecipitates, which were resolved by SDS-PAGE. Proteins were transferred onto nitrocellulose membranes (Immobilon P; Millipore, Bedford, MA, USA) that were subsequently blocked using Odyssey blocking buffer (LI-COR Bioscience, Lincoln, NE, USA) at room temperature for $1 \mathrm{~h}$, then incubated at $4{ }^{\circ} \mathrm{C}$ overnight with primary antibodies: p-p65 (1:500), p65 (1:500), p-IKK $\alpha / \beta(1: 800)$, IKK $\alpha / \beta$ $(1: 800)$, I $\kappa$ B $(1: 800), p-1 \kappa B(1: 800)$, GAPDH $(1: 1000)$, p-Syk $(1: 1000)$, Syk $(1: 1000), \operatorname{CARD} 9(1: 800), \operatorname{Bcl} 10(1: 800), \operatorname{MALT} 1(1: 800)$ and $\beta$-actin $(1: 1000)$. The membranes were washed and incubated with fluorescent secondary antibodies (Alexa Fluor 680 or IRDye 800 , Rockland Immunochemicals, Gilbertsville, PA, USA) for $1 \mathrm{~h}$, and then blots were analyzed with the Odyssey infrared imaging system and Odyssey software.

For blocking experiments, WT BMDMs were preincubated with either isotype control IgGs or neutralizing antibodies: anti-VEGF Ab $(0.5 \mu \mathrm{g} / \mathrm{ml})$, anti-IL-15 Ab $(0.3 \mu \mathrm{g} / \mathrm{ml})$ and anti-MIG Ab $(0.15 \mu \mathrm{g} / \mathrm{ml})$ for $2 \mathrm{~h}$, then followed by SL4 cell coculture. Twenty-four hours later, the protein was extracted from WT BMDMs, and the phosphorylation levels of Syk were examined by western blot.

RNA analysis. Total RNA from human colon carcinoma, adjacent normal colon tissues, metastatic foci in mouse livers, BMDMs and RAW 264.7 cells were extracted using TRIZOL (Invitrogen, Carlsbad, CA, USA), and first-strand CDNA was synthesized using Superscript II (Invitrogen). Quantitative real-time PCR involved the iCycler iQ system (Bio-Rad Laboratories). The primer sequences were as follows:

\begin{tabular}{|c|c|c|}
\hline Primer & Forward & Reverse \\
\hline $\begin{array}{l}\text { Human } \\
\text { CARD3 }\end{array}$ & 5'-САСТССАTGСTCTTCAGCAA-3' & 5'-CTGGTTAAGGCAGGCTTCTG-3' \\
\hline $\begin{array}{l}\text { Human } \\
\text { CARD5 }\end{array}$ & 5'-TGACGGATGAGCAGTACCAG-3' & 5'-CAGGCTGGTGTGAAACTGAA-3' \\
\hline $\begin{array}{l}\text { Human } \\
\text { CARD6 }\end{array}$ & 5'-GACTGCCAAGACCCATTTGT-3' & 5'-TTGGAGGCTACTGCCCTAGA-3' \\
\hline $\begin{array}{l}\text { Human } \\
\text { CARD9 }\end{array}$ & 5'-GCACCAGAGTGAGGAGAAGG-3' & 5'-CTTCATGAGGCTGTGCTTGA-3' \\
\hline $\begin{array}{l}\text { Human } \\
\text { CARD11 }\end{array}$ & 5'-CACCATGTCCCTGAAGTGTG-3' & 5'-TATGGTGCCCATATCCAGGT-3' \\
\hline $\begin{array}{l}\text { Human } \\
\text { CARD12 }\end{array}$ & 5'-GCAAGGCTCTGACCAAGTTC- $3^{\prime}$ & 5'-TGTCTGCTTCCTGATTGTGC-3' \\
\hline $\begin{array}{l}\text { Human } \\
\text { CARD14 }\end{array}$ & 5'-CACTTGCTGGATTTGCTGAA-3' & 5'-GACGTCAGGGTTGTGGAACT-3' \\
\hline $\begin{array}{l}\text { Human } \\
\text { GAPDH }\end{array}$ & 5'-ACAGTCAGCCGCATCTTCTT-3' & 5'-ACGACCAAATCCGTTGACTC-3' \\
\hline $\begin{array}{l}\text { Mouse } \\
\text { CARD3 }\end{array}$ & 5'-AAATCATCCCCCACAGGAG-3' & 5'-GGTCCAGGAGAACCAGTGTT-3' \\
\hline $\begin{array}{l}\text { Mouse } \\
\text { CARD5 }\end{array}$ & 5'-GAGCAGCTGCAAACGACTAA-3' & 5'-GTCCACAAAGTGTCCTGTTCTG-3 \\
\hline $\begin{array}{l}\text { Mouse } \\
\text { CARD6 }\end{array}$ & 5'-ATTTTGTGGCCCTCCAAGA-3' & 5'-TTGAAAGTGGGCAACATGG-3' \\
\hline $\begin{array}{l}\text { Mouse } \\
\text { CARD9 }\end{array}$ & $\begin{array}{l}5^{\prime}-\text { CCGCTCGAGGTGCACAG } \\
{\text { CCTCCTT- } 3^{\prime}}\end{array}$ & $\begin{array}{l}5^{\prime} \text {-CCCAAGCTTTGGGGAGCAG } \\
\text { CTGAG-3' }\end{array}$ \\
\hline $\begin{array}{l}\text { Mouse } \\
\text { CARD10 }\end{array}$ & $5^{\prime}$-TGCAGGGCGAGCTACAGT- $3^{\prime}$ & 5'-GCAGATCCTCCATCTCTTGC-3' \\
\hline $\begin{array}{l}\text { Mouse } \\
\text { CCL17 }\end{array}$ & 5'-ATAAAACGGCCTGTGACCAG-3' & 5'-TTTGTGTTCGCCTGTAGTGC-3' \\
\hline $\begin{array}{l}\text { Mouse } \\
\text { CCL22 }\end{array}$ & 5'-СТССССТСТАТСССТTССАG-3' & 5'-ATCAGGGCATCAAAACAAGG-3' \\
\hline $\begin{array}{l}\text { Mouse } \\
\text { YM1 }\end{array}$ & 5'-GAAGGAGCCACTGAGGTCTG-3' & 5'-CACGGCACCTCCTAAATTGT-3' \\
\hline $\begin{array}{l}\text { Mouse } \\
\text { FIZZ1 }\end{array}$ & 5'-TTGCAACTGCCTGTGCTTAC-3' & 5'-CTGGGTTCTCCACCTCTTCA-3' \\
\hline $\begin{array}{l}\text { Mouse } \\
\text { IL12-p35 }\end{array}$ & $\begin{array}{l}\text { 5'-CCATCAGCAGATCATTCTAGA } \\
\text { CAA- } 3^{\prime}\end{array}$ & 5'-CGCCATTATGATTCAGAGACTG-3 \\
\hline $\begin{array}{l}\text { Mouse } \\
\text { IL12-p40 }\end{array}$ & 5'-GATTCAGACTCCAGGGGACA-3' & 5'-TGGTTAGCTTCTGAGGACACATC-3' \\
\hline $\begin{array}{l}\text { Mouse } \\
\text { CXCL9 }\end{array}$ & 5'-TGAATTTCCTTGCCACCTTC-3' & 5'- GCCCTGATCTTTCCATTTCA-3' \\
\hline $\begin{array}{l}\text { Mouse } \\
\text { CXCL10 }\end{array}$ & 5'-TCCTTGTCCTCCCTAGCTCA-3' & 5'-ATAACCCCTTGGGAAGATGG-3' \\
\hline $\begin{array}{l}\text { Mouse } \\
\text { iNOS }\end{array}$ & 5'-GGGCTGTCACGGAGATCA-3' & 5'CCATGATGGTCACATTCTGC3' \\
\hline $\begin{array}{l}\text { Mouse } \\
\text { VEGFR1 }\end{array}$ & 5'-TGAGGAGCTTTCACCGAACT-3' & 5'-TATCTTCATGGAGGCCTTGG-3' \\
\hline $\begin{array}{l}\text { Mouse } \\
\text { TGF- } \beta\end{array}$ & 5'-TGGAGCAACATGTGGAACTC-3' & 5'-CAGCAGCCGGTTACCAAG-3' \\
\hline $\begin{array}{l}\text { Mouse } \\
\text { IL-10 }\end{array}$ & 5'-CCAGGGAGATCCTTTGATGA-3' & 5'-AACTGGCCACAGTTTTCAGG-3' \\
\hline $\begin{array}{l}\text { Mouse } \\
\text { IL- } 1 \alpha\end{array}$ & 5'-AGACCATCCAACCCAGATCA-3' & 5'-TGACAAACTTCTGCCTGACG-3' \\
\hline $\begin{array}{l}\text { Mouse } \\
\text { IL-1 } \beta\end{array}$ & 5'-GCCCATCCTCTGTGACTCAT-3' & 5'-AGGCCACAGGTATTTTTGTCG-3' \\
\hline $\begin{array}{l}\text { Mouse } \\
\text { CCR2 }\end{array}$ & 5'-АTTCTCCACACCCTGTTTCG-3' & 5'-GATTCCTGGAAGGTGGTCAA-3' \\
\hline $\begin{array}{l}\text { Mouse } \\
\text { tubulin }\end{array}$ & 5'-TCTAACCCGTTGCTATCATGC-3' & 5'-GCCATGTTCCAGGCAGTAG-3' \\
\hline
\end{tabular}

Supernatants array assay for secreted cytokines. The culture supernatants were collected and clarified by centrifugation, followed by analysis for protein levels of cytokines using Bio-Plex Cytokine Assay kit (Bio-Rad Laboratories), according to the manufacturer's instructions. Fifty microliters each of cytokine standards, samples and blanks was incubated with $25 \mu$ lanticytokineconjugated beads in 96-well filter plates for $30 \mathrm{~min}$ at RT with agitation (1100 r.p.m. for 30 s, then 300 r.p.m. for $30 \mathrm{~min}$ ). Plates were subsequently washed three times on the magnetic plate carrier with $100 \mu$ l Bio-Plex (Bio-Rad Laboratories) wash buffer per well. This was followed by the addition of $25 \mu$ l diluted biotinylated detection antibody and further incubation with agitation for $30 \mathrm{~min}$ at RT. After three washes (described above), $25 \mu \mathrm{l}$ streptavidin-PE was added, and the plates were incubated for $10 \mathrm{~min}$ at RT with agitation. Finally, after three washes, beads were subsequently resuspended in $125 \mu \mathrm{l}$ Bio-Plex assay buffer, vortexed for $30 \mathrm{~s}$ at 1100 r.p.m. and further incubated for $2 \mathrm{~min}$ at 300 r.p.m. Measurements and data analyses were performed with the Bio-Plex system in combination with the Bio-Plex Manager software 6.0 (Bio-Rad Laboratories).

Statistical analysis. Data analysis involved use of GraphPad software (GraphPad Prism version 5.00 for Windows, GraphPad Software, San Diego, CA, USA). Results are expressed as mean \pm S.E.M. Differences were analyzed by $t$-test or ANOVA, and results were considered significant at $P<0.05$.

\section{Conflict of Interest}

The authors declare no conflict of interest.

Acknowledgements. We thank Ying Wang and Shu-Lan Qiu for the excellent technical support in three-dimensional nano gel culture, Shuai Zheng for the help with BM transplantation and Chun-Mei Piao for the help with in vivo bioluminescence imaging. This study was supported by grants from Chinese Ministry of Science and Technology (2009CB522205), Chinese High Technology Research and Development Program (2012AA02A201), National Science Foundation of China (81170120) and Beijing Nova Program (Z121107002512041).

1. Hanahan D, Coussens LM. Accessories to the crime: functions of cells recruited to the tumor microenvironment. Cancer Cell 2012; 21: 309-322.

2. Valastyan S, Weinberg RA. Tumor metastasis: molecular insights and evolving paradigms. Cell 2011; 147: 275-292.

3. Mantovani A, Sozzani S, Locati M, Allavena P, Sica A. Macrophage polarization: tumorassociated macrophages as a paradigm for polarized M2 mononuclear phagocytes. Trends Immunol 2002; 23: 549-555.

4. Solinas G, Germano G, Mantovani A, Allavena P. Tumor-associated macrophages (TAM) as major players of the cancer-related inflammation. J Leukoc Biol 2009; 86: 1065-1073.

5. Condeelis J, Pollard JW. Macrophages: obligate partners for tumor cell migration, invasion, and metastasis. Cell 2006; 124: 263-266.

6. Zaynagetdinov R, Sherrill TP, Polosukhin VV, Han W, Ausborn JA, McLoed AG et al. A critical role for macrophages in promotion of urethane-induced lung carcinogenesis. J Immunol 2011; 187: 5703-5711.

7. Lu-Emerson C, Snuderl M, Kirkpatrick ND, Goveia J, Davidson C, Huang Y et al. Increase in tumor-associated macrophages after antiangiogenic therapy is associated with poor survival among patients with recurrent glioblastoma. Neuro Oncol 2013; 15: 1079-1087.

8. Ohno S, Ohno Y, Suzuki N, Kamei T, Koike K, Inagawa H et al. Correlation of histological localization of tumor-associated macrophages with clinicopathological features in endometrial cancer. Anticancer Res 2004; 24: 3335-3342.

9. Shabo I, Stal O, Olsson H, Dore S, Svanvik J. Breast cancer expression of CD163, a macrophage scavenger receptor, is related to early distant recurrence and reduced patient survival. Int J Cancer 2008; 123: 780-786.

10. Kurahara H, Shinchi H, Mataki Y, Maemura K, Noma H, Kubo F et al. Significance of M2polarized tumor-associated macrophage in pancreatic cancer. J Surg Res 2011; 167: e211-e219.

11. Lee CH, Espinosa I, Vrijaldenhoven S, Subramanian S, Montgomery KD, Zhu S et al. Prognostic significance of macrophage infiltration in leiomyosarcomas. Clin Cancer Res 2008; 14: 1423-1430.

12. Komohara Y, Ohnishi K, Kuratsu J, Takeya M. Possible involvement of the M2 anti-inflammatory macrophage phenotype in growth of human gliomas. J Pathol 2008; 216: $15-24$.

13. Qian B, Deng Y, Im JH, Muschel RJ, Zou Y, Li J et al. A distinct macrophage population mediates metastatic breast cancer cell extravasation, establishment and growth. PLoS One 2009; 4: e6562. 
14. Qian BZ, Pollard JW. Macrophage diversity enhances tumor progression and metastasis. Cell 2010; 141: 39-51.

15. Ruland J. CARD9 signaling in the innate immune response. Ann N Y Acad Sci 2008; 1143 35-44.

16. Hsu YM, Zhang Y, You Y, Wang D, Li H, Duramad O et al. The adaptor protein CARD9 is required for innate immune responses to intracellular pathogens. Nat Immunol 2007; 8: 198-205.

17. Nakamura S, Matsumoto T, Yada S, Hirahashi M, Suekane H, Yao T et al. Overexpression of caspase recruitment domain (CARD) membrane-associated guanylate kinase 1 (CARMA1) and CARD9 in primary gastric B-cell lymphoma. Cancer 2005; 104: 1885-1893.

18. Zhou Y, Ye H, Martin-Subero JI, Hamoudi R, Lu YJ, Wang R et al. Distinct comparative genomic hybridisation profiles in gastric mucosa-associated lymphoid tissue lymphomas with and without $t(11 ; 18)(q 21 ; q 21)$. Br J Haematol 2006; 133: 35-42.

19. Ullrich E, Bonmort M, Mignot G, Kroemer G, Zitvogel L. Tumor stress, cell death and the ensuing immune response. Cell Death Differ 2008; 15: 21-28.

20. Joyce JA, Pollard JW. Microenvironmental regulation of metastasis. Nat Rev Cancer 2009; 9: 239-252.

21. Qian BZ, Li J, Zhang H, Kitamura T, Zhang J, Campion LR et al. CCL2 recruits inflammatory monocytes to facilitate breast-tumour metastasis. Nature 2011; 475: 222-225.

22. Qing W, Fang WY, Ye L, Shen LY, Zhang XF, Fei XC et al. Density of tumor-associated macrophages correlates with lymph node metastasis in papillary thyroid carcinoma. Thyroid 2012; 22: 905-910.

23. Obeid E, Nanda R, Fu YX, Olopade OI. The role of tumor-associated macrophages in breast cancer progression (review). Int J Oncol 2013; 43: 5-12.

24. Bailey C, Negus R, Morris A, Ziprin P, Goldin R, Allavena $P$ et al. Chemokine expression is associated with the accumulation of tumour associated macrophages (TAMs) and progression in human colorectal cancer. Clin Exp Metastasis 2007; 24: 121-130.

25. Ishigami S, Natsugoe S, Tokuda K, Nakajo A, Okumura $H$, Matsumoto $M$ et al. Tumor-associated macrophage (TAM) infiltration in gastric cancer. Anticancer Res 2003; 23: 4079-4083.

26. Martinez FO, Helming L, Gordon S. Alternative activation of macrophages: an immunologic functional perspective. Annu Rev Immunol 2009; 27: 451-483.

27. Jaiswal S, Jamieson CH, Pang WW, Park CY, Chao MP, Majeti R et al. CD47 is upregulated on circulating hematopoietic stem cells and leukemia cells to avoid phagocytosis. Cell 2009; 138: 271-285.

28. Roca H, Varsos ZS, Sud S, Craig MJ, Ying C, Pienta KJ. CCL2 and interleukin-6 promote survival of human $\mathrm{CD11b}+$ peripheral blood mononuclear cells and induce M2-type macrophage polarization. J Biol Chem 2009; 284: 34342-34354.

29. Mantovani A, Allavena P, Sica A, Balkwill F. Cancer-related inflammation. Nature 2008: 454: 436-444.

30. Solinas G, Schiarea S, Liguori M, Fabbri M, Pesce S, Zammataro L et al. Tumor-conditioned macrophages secrete migration-stimulating factor: a new marker for M2-polarization, influencing tumor cell motility. J Immunol 2010; 185: 642-652.
31. Chang CP, Su YC, Hu CW, Lei HY. TLR2-dependent selective autophagy regulates NF-kappaB lysosomal degradation in hepatoma-derived M2 macrophage differentiation. Cell Death Differ 2013; 20: 515-523.

32. DeNardo DG, Barreto JB, Andreu P, Vasquez L, Tawfik D, Kolhatkar N et al. CD4(+) T cells regulate pulmonary metastasis of mammary carcinomas by enhancing protumor properties of macrophages. Cancer Cell 2009; 16: 91-102.

33. Hagemann T, Lawrence T, McNeish I, Charles KA, Kulbe H, Thompson RG et al. "Re-educating" tumor-associated macrophages by targeting NF-kappaB. J Exp Med 2008 205: 1261-1268.

34. Gross O, Gewies A, Finger K, Schafer M, Sparwasser T, Peschel C et al. Card9 controls a non-TLR signalling pathway for innate anti-fungal immunity. Nature 2006; 442 651-656.

35. Bi L, Gojestani S, Wu W, Hsu YM, Zhu J, Ariizumi K et al. CARD9 mediates dectin-2-induced lkappaBalpha kinase ubiquitination leading to activation of NF-kappaB in response to stimulation by the hyphal form of Candida albicans. J Biol Chem 2010; 285 25969-25977.

36. Mocsai A, Ruland J, Tybulewicz VL. The SYK tyrosine kinase: a crucial player in diverse biological functions. Nat Rev Immunol 2010; 10: 387-402.

37. Issa A, Le TX, Shoushtari AN, Shields JD, Swartz MA. Vascular endothelial growth factor-C and $\mathrm{C}-\mathrm{C}$ chemokine receptor 7 in tumor cell-lymphatic cross-talk promote invasive phenotype. Cancer Res 2009; 69: 349-357.

38. Morimoto-Tomita M, Ohashi Y, Matsubara A, Tsuiji M, Irimura T. Mouse colon carcinoma cells established for high incidence of experimental hepatic metastasis exhibit accelerated and anchorage-independent growth. Clin Exp Metastasis 2005; 22: 513-521.

39. Lammers B, Chandak PG, Aflaki E, Van Puijvelde GH, Radovic B, Hildebrand RB et al. Macrophage adipose triglyceride lipase deficiency attenuates atherosclerotic lesion development in low-density lipoprotein receptor knockout mice. Arterioscler Thromb Vasc Biol 2011; 31: 67-73.

40. Yang M, Zheng J, Miao Y, Wang Y, Cui W, Guo J et al. Serum-glucocorticoid regulated kinase 1 regulates alternatively activated macrophage polarization contributing to angiotensin II-induced inflammation and cardiac fibrosis. Arterioscler Thromb Vasc Biol 2012; 32: 1675-1686.

(i) (9) $\Theta$ This work is licensed under a Creative Commons Attribution-NonCommercial-NoDerivs 3.0 Unported License. The images or other third party material in this article are included in the article's Creative Commons license, unless indicated otherwise in the credit line; if the material is not included under the Creative Commons license, users will need to obtain permission from the license holder to reproduce the material. To view a copy of this license, visit http://creativecommons.org/licenses/by-nc-nd/3.0/ 